\title{
How the Exposure to Beauty Ideals on Social Networking Sites Influences Body Image: A Systematic Review of Experimental Studies
}

\author{
Giulia Fioravanti $^{1}\left[\right.$ S Sara Bocci Benucci ${ }^{1} \cdot$ Giulia Ceragioli $^{1} \cdot$ Silvia Casale $^{1}$
}

Received: 7 September 2021 / Accepted: 1 January 2022 / Published online: 15 January 2022

(c) The Author(s) 2022

\begin{abstract}
Sharing and viewing photos on social networking sites (SNSs) have been identified as particularly problematic for body image. Although correlational research to date has established that SNS use is associated with increased body dissatisfaction, only experimental studies can enhance confidence in the conclusions drawn. For this reason, this systematic review synthesizes data from 43 experimental studies $(N=8637 ; \% F=89.56$; mean age $=21.58 \pm 1.78)$ examining the effect of viewing idealized images (i.e., attractive, thin, and fit) and body positive content on SNSs on body image. Two studies were conducted on adolescents. Each study had slight variations in how the images were presented for each category (e.g., selfies and photos taken by others). The wide variability in experimental stimuli and psychological moderators used in the published research make a systematic review more feasible and meaningful than a meta-analysis. Findings indicate that viewing idealized images on SNSs lead to increased body dissatisfaction among young women and men. State appearance comparison (i.e., engaging in social comparison while viewing images) significantly mediated the effect, whereas trait appearance comparison (i.e., the relatively stable general tendency to engage in social comparison) was a significant moderator. Mixed results were found regarding the exposure to body positive images/captions. Viewing images on SNSs depicting unattainable beauty ideals leads young people to feel dissatisfied about their bodies, with appearance comparison processing playing an important role. More research is required to assess the long-term effects.
\end{abstract}

Keywords Body image $\cdot$ Social networking sites $\cdot$ Body dissatisfaction $\cdot$ Body positive $\cdot$ Systematic review

\section{Introduction}

An emerging body of research has evidenced the negative influence of using and being exposed to social networking sites (SNSs) on body image. Specifically, a wide number of correlational studies have found that SNSs use is associated with body dissatisfaction and body image disturbance among young women and men (for a systematic review, see Holland \& Tiggemann, 2016; for a meta-analysis, see Saiphoo \& Vahedi, 2019). Since only experimental studies can enhance confidence in the conclusions drawn, over the last ten years a growing number of studies have used experimental methods to test whether people feel worse about their bodies after exposure to different types of beauty ideals images on SNSs (i.e., attractive, thin, and fit bodies) than after exposure to

Giulia Fioravanti

giulia.fioravanti@unifi.it

1 Department of Health Sciences, Psychology Unit, University of Florence, Via di San Salvi 12, 50135 Florence, Italy appearance-neutral images. However, to date no previous systematic review has been conducted on the available experimental research in this area, helping to clarify which types of images that people view every day on SNSs have a negative impact on body image and for which types of individuals. This study aims to fill this gap by systematically reviewing the growing body of experimental studies that has investigated the influence of SNSs use on body image. The effect of viewing various types of SNSs idealized images on different body image outcomes, as well as the potential mediating/moderating variables will be examined.

Body image can be defined as a "person's perceptions, thoughts, and feelings about their body" (Grogan, 2008, p. 4). Body dissatisfaction occurs when the evaluation of personal body image is negative and when a perceived discrepancy between real and ideal body occurs (Cash \& Szymanski, 1995). Over the past few decades, body dissatisfaction has been shown to be associated with eating and weight disorders (e.g., Brownell \& Walsh, 2017), depression (e.g., Goldfield et al., 2010), suicidality (Crow et al., 2008), and 
decreased quality of life (e.g., Griffiths et al., 2016). Because of its harmful effects and its high prevalence (e.g., in the U.S., ranging from 11 to $72 \%$ in women and from 8 to $61 \%$ in men; Fiske et al., 2014), body dissatisfaction has been identified as an important public health issue (e.g., Bucchianeri \& Neumark-Sztainer, 2014).

Body dissatisfaction is considered to be influenced by sociocultural factors, with mass media being the most impactful one (e.g., Tiggemann, 2002). Ideal body shapes conveyed by traditional mass media, such as magazines and television, comprise unattainably thin and toned bodies, exalting slenderness and weight loss (Groesz et al., 2002). The relationship between traditional media exposure and body dissatisfaction has been supported by a considerable number of correlational and experimental studies both among women (for a meta-analysis see Grabe et al., 2008) and men (for a meta-analysis see Barlett et al., 2008).

According to the sociocultural theory of body dissatisfaction (Thompson et al., 1999) there are two mechanisms involved in this relationship: (i) internalization of appearance ideals (e.g., thin, muscular, and fit ideals); (ii) appearance-based social comparison. Specifically, frequent media exposure leads individuals to internalize the thin ideal as beautiful and desirable, compare themselves to these idealized images, and feel dissatisfied with their body and appearance as a result (e.g., Stice et al., 1994). Another important framework for understanding the effect of media exposure on body image is offered by the objectification theory (Fredrickson \& Roberts, 1997). In Western societies, the female body is considered as an object to be looked at and evaluated mainly based on physical appearance. The pervasiveness of this cultural message leads women to assume an observer's point of view, and to consider their own bodies as an object to be looked at and evaluated in terms of appearance, a mechanism named self-objectification (Fredrickson $\&$ Roberts, 1997). Self-objectification occurs when a woman starts to habitually and constantly monitor her own body appearance. This body surveillance increases body shame and anxiety (Fredrickson \& Roberts, 1997). Research evidence has demonstrated that exposure to sexualized fashion magazine images results in both state self-objectification and body dissatisfaction (e.g., Harper \& Tiggemann, 2008).

\section{Body Image and Social Networking Sites}

Although traditional media are still largely used, other types of "new" media are being increasingly diffused, most evidently the SNSs. SNSs are online platforms where users can create and share content with other users (Kaplan \& Haenlein, 2010). These sites differ from traditional media in two main aspects: (i) they are interactive; (ii) the content is mostly generated by peers (Tiggemann \& Velissaris, 2020).
Users are simultaneously information sources and receivers, they can actively decide their participation by creating their own profiles and posts, browsing the information posted by other users and interacting with them through "likes" and comments.

Sharing and viewing photos on SNSs have been identified as particularly problematic for body image (e.g., Cohen et al., 2017). In detail, engagement in photo activities on Facebook and following appearance-focused accounts on Instagram ('celebrities') was associated with both thinideal internalization and body surveillance, thus supporting the sociocultural and objectification theories of media and body image (Fredrickson \& Roberts, 1997; Thompson et al., 1999). Indeed, like traditional media, SNSs are often appearance-focused since users post photos in which they look good and attractive, enhanced by the application of filters or digital editing tools and posed (e.g., Cohen et al., 2017). As a result, many of the images presented on SNSs are idealized and unrealistically attractive, thus inducing body dissatisfaction. In support of this, a consistent body of research has shown that SNS use is associated with body image concerns and disordered eating (for a systematic review, see Holland \& Tiggemann, 2016; for a meta-analysis, see Saiphoo \& Vahedi, 2019). In particular, the systematic review conducted on twenty observational or experimental studies provides evidence that SNS use is associated with increased body dissatisfaction and disordered eating among both women and men. Internalization, appearance comparison and self-objectification were found to explain the detrimental effect of SNS use on body image (Holland \& Tiggemann, 2016), providing support for the application of both the sociocultural (Thompson et al., 1999) and the objectification theory (Fredrickson \& Roberts, 1997) in the field of SNSs. The recent meta-analysis conducted on 63 correlational studies found a small, positive relationship $(r=0.169)$ between SNSs use and body image disturbance (Saiphoo \& Vahedi, 2019). Studies that assessed appearance-focused social media use obtained a stronger effect size $(r=0.305)$ than those that investigated general social media use $(r=0.114)$. Moreover, higher effect sizes were found for cognitive and behavioral dimensions of body image compared to the general/evaluative dimension. However, overall effect size was found to be smaller compared to results on the effect of traditional media on body image (e.g., Grabe et al., 2008) suggesting that the relationship between social media and body image needs further research to be better understood.

Over the last ten years a growing number of experimental studies investigating the effects of the exposure to different types of beauty ideals via SNSs on body image have been conducted. The majority of these studies have used experimental methods to test whether women feel worse about their bodies after exposure to idealized images on 
SNSs than after exposure to other types of images (e.g., Brown \& Tiggemann, 2016). In a typical experiment, participants complete assessments of body image-related constructs, and then they are randomly assigned to view images taken from Instagram or Facebook of the ideal body (e.g., attractive, thin, fit; experimental condition) or images that are considered appearance-neutral (e.g., travel; control condition). Following the experimental manipulation, participants are asked to complete post-test measures of body image-related constructs. An increase in body dissatisfaction following exposure to idealized Instagram images of thin and attractive women relative to control images was found (e.g., Cohen et al., 2019; Tiggemann \& Zaccardo, 2015). Moreover, also the exposure to fitspiration images (i.e., people usually exercising, or dressed in exercise outfits) was associated with the development of body image dissatisfaction (e.g., Griffiths \& Stefanovski, 2019; Prichard et al., 2018; Sherlock \& Wagstaff, 2018; Yee et al., 2020). Content analyses showed that fitspiration images, albeit focused on fitness and health, foster weight loss and place particular value on physical appearance, depicting only thin and toned models (Carrotte et al., 2017).

In response to fitspiration and other appearance-focused beauty trends, the 'body-positive' movement has rapidly grown in recent years (Tylka \& Wood-Barcalow, 2015). This trend comprises posts of images of women (e.g., selfies, posed or unposed photos) showing their larger bodies with pride or their 'real' bodies without filters or digital alterations (Sastre, 2014). Body-positive trends on social media aim to face thin ideals and to disseminate body appreciation and acceptance among women (Cwynar-Horta, 2016). Body appreciation has been defined as "appreciating the features, functionality, and health of the body rather than focusing solely on its appearance" (Tylka \& Wood-Barcalow, 2015, p. 123). Experimental studies show the protective role of body appreciation as opposed to the negative impacts of exposure to traditional media (Andrew et al., 2015; Halliwell, 2013). Recently, the effect of viewing Instagram's body-positive images on young women's body image was experimentally examined, showing that body satisfaction improved among participants who were briefly exposed to body-positive images compared to those exposed to thin-ideal and appearance-neutral images (Cohen et al., 2019) as well as compared to those exposed to fitspiration and appearanceneutral images (Serlin, 2020). However, two other recent experimental studies (Brown \& Tiggemann, 2020; Tiggemann et al., 2020b) found no positive effect of body-positive captions attached to Instagram images (of both unknown peers and celebrities) on either body dissatisfaction or body appreciation, nor on social comparison, concluding that the addition of body-positive captions by attractive celebrities or peers does not serve to improve women's body image.

\section{The Current Study}

Although correlational research to date has established significant associations between SNS use and body dissatisfaction only experimental studies can enhance confidence in the conclusions drawn. For this reason, the present paper aims to systematically review the growing body of experimental research that has investigated the influence of SNSs use on body image. This was accomplished by examining the effect of viewing idealized images (i.e., attractive, thin, and fit) on SNSs on body image, as well as examining the mediating/moderating effect of previously identified underlying mechanisms (such as appearance comparison, thin ideal internalization, self-objectification). On the basis of the correlational literature on the association between SNS use and body image, an overall significant effect is expected, such as viewing idealized models of beauty on SNSs would increase the immediate sense of body dissatisfaction compared to viewing appearance-neutral images. It is also expected that thinideal internalization, appearance comparison and selfobjectification would emerge as significant moderating/ mediating variables.

Moreover, given the contradictory results related to the effect of body-positive content on body image, also those experimental studies aimed to examine the effect of the exposure to body-positive images on body satisfaction and appreciation were systematically reviewed. In this case, no prediction was made since this area of research is relatively new, and therefore, the number of studies in this field is small.

\section{Methods}

This systematic review was conducted following the Preferred Reporting Items for Systematic reviews and MetaAnalyses (PRISMA) guidelines provided by Liberati et al. (2015). PROSPERO REGISTRATION NUMBER: CRD42021233180.

\section{Eligibility Criteria}

Studies were eligible for inclusion if the following criteria were met: (a) original article; (b) English language; (c) quantitative research; (d) experimental design; (e) examining the effect of the exposure to SNSs idealized images or to body-positive images on some dimension of body image; (f) reported effect size. Studies were excluded if they did not meet all the eligibility criteria listed above. 


\section{Search Procedure and Study Selection}

To identify eligible studies a search was performed in October 2020 on Medline, Scopus, Web of Science, and Science Direct databases using the following search string: "(Social Media OR Social Network OR SNS OR Facebook OR Instagram OR Pinterest OR Thinspiration OR Fitspiration OR Bodypositive OR Bopo AND (Body image OR Body appearance OR Body dissatisfaction OR Body satisfaction OR Body appreciation OR Positive body image OR Body disturbance)". References of the collected articles were also scanned for additional relevant studies (backward search).

A diagrammatic representation of the search and screening procedures is shown in Fig. 1. First, identified duplicates were eliminated, then each article's title and abstract were screened independently by two authors (S.B.B and G.C.; conflicts solved by a third author: G.F.) and articles that were not considered eligible for inclusion were excluded. For the remaining articles a full-text examination was conducted.

\section{Data Extraction and Risk of Bias}

The following information was extracted for each study: authors and year of publication, the country where the participants lived (and the \% Caucasian), sample size (and the target population), mean age of sample and percentage of females, mean body mass index (BMI) of sample, the study design and a description of the experimental conditions, type of images used, body image dimension and measures, key findings, and effect sizes (see Table 1).

The risk of bias within each individual study was measured with a quality assessment that was conducted using the American Dietetic Association Quality Criteria Checklist (QCC; American Dietetic Association, 2005) by two independent researchers (S.B.B. and G.F.; conflicts solved by S.C.). This measure was used to conduct quality assessments of body image research before (e.g., McComb \& Mills, 2020; Santhira et al., 2018). The QCC consists of 10 criteria that appraise the scientific validity of each study, and provides an overall quality rating as positive, neutral or negative. A positive overall score was obtained by a study if most of the answers to validity criteria questions were 'yes', including criteria 2 (i.e., the selection of study subjects was free from bias), 3 (i.e., study groups were comparable), 6 (i.e., the study procedure was described in adequate detail), and 7 (i.e., the outcomes were clearly defined and measurements were valid and reliable), and at least one additional criterion was also answered 'yes'. A neutral score was given
Fig. 1 PRISMA flowchart of the search and screening procedures

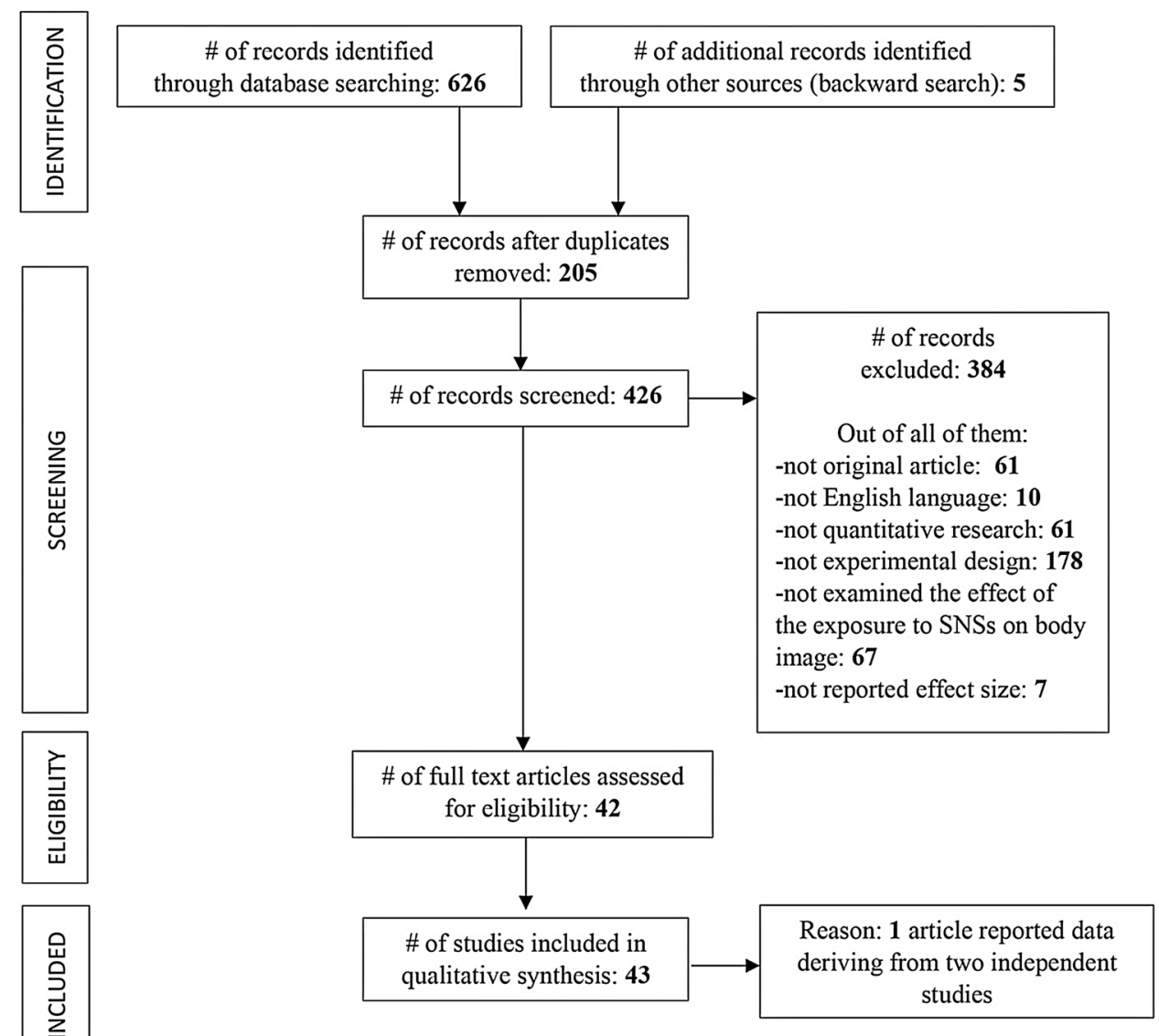




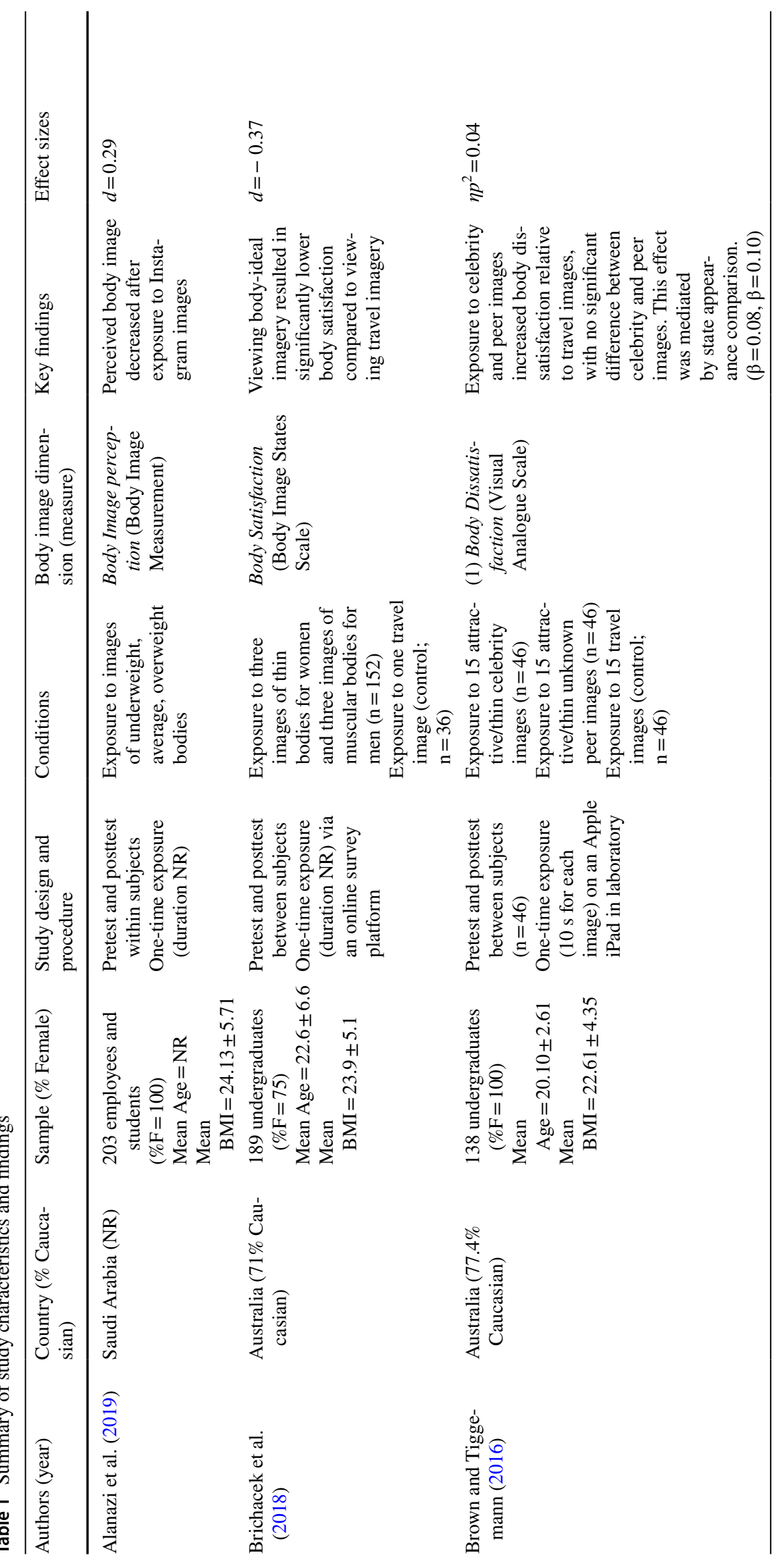




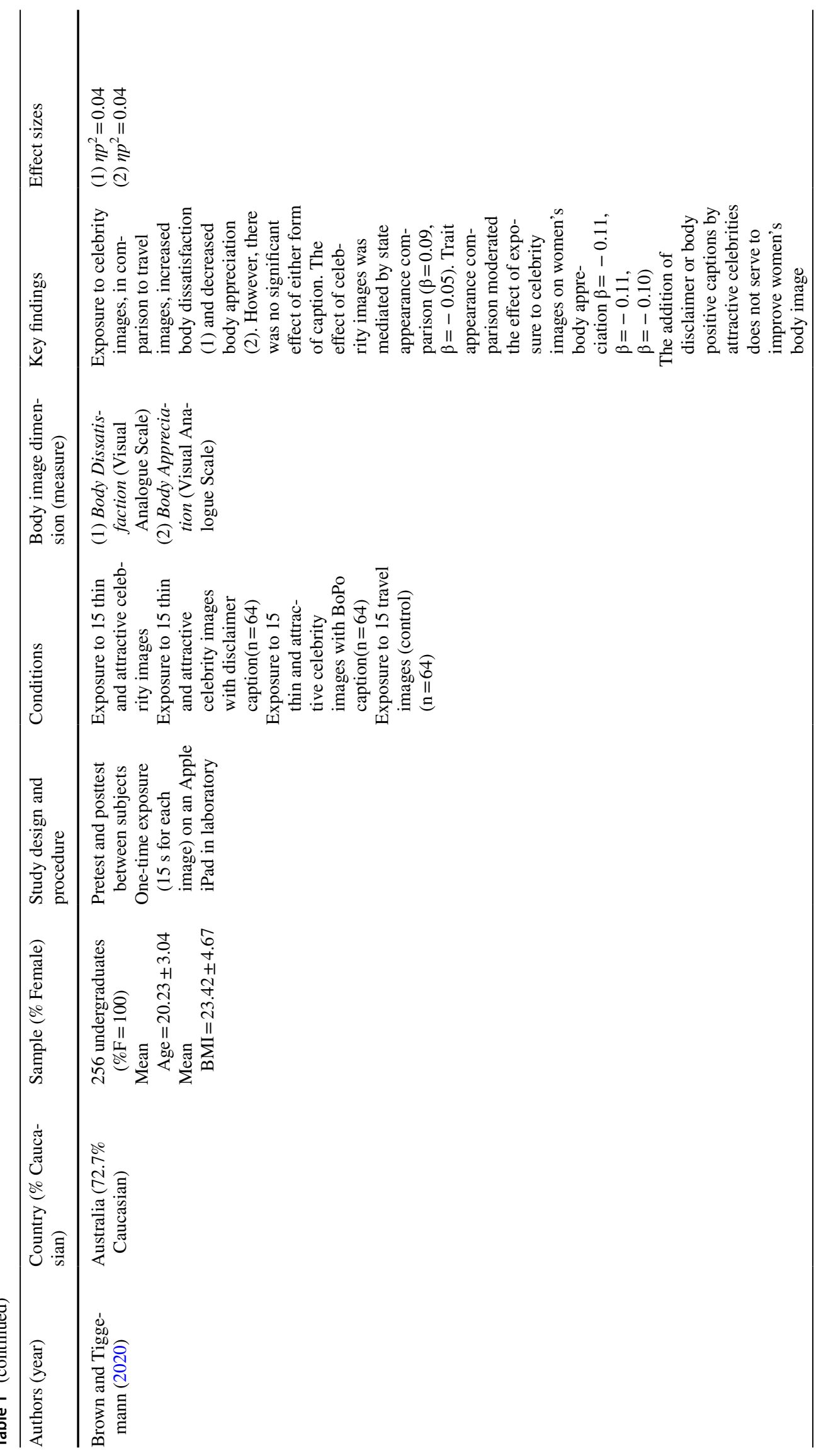




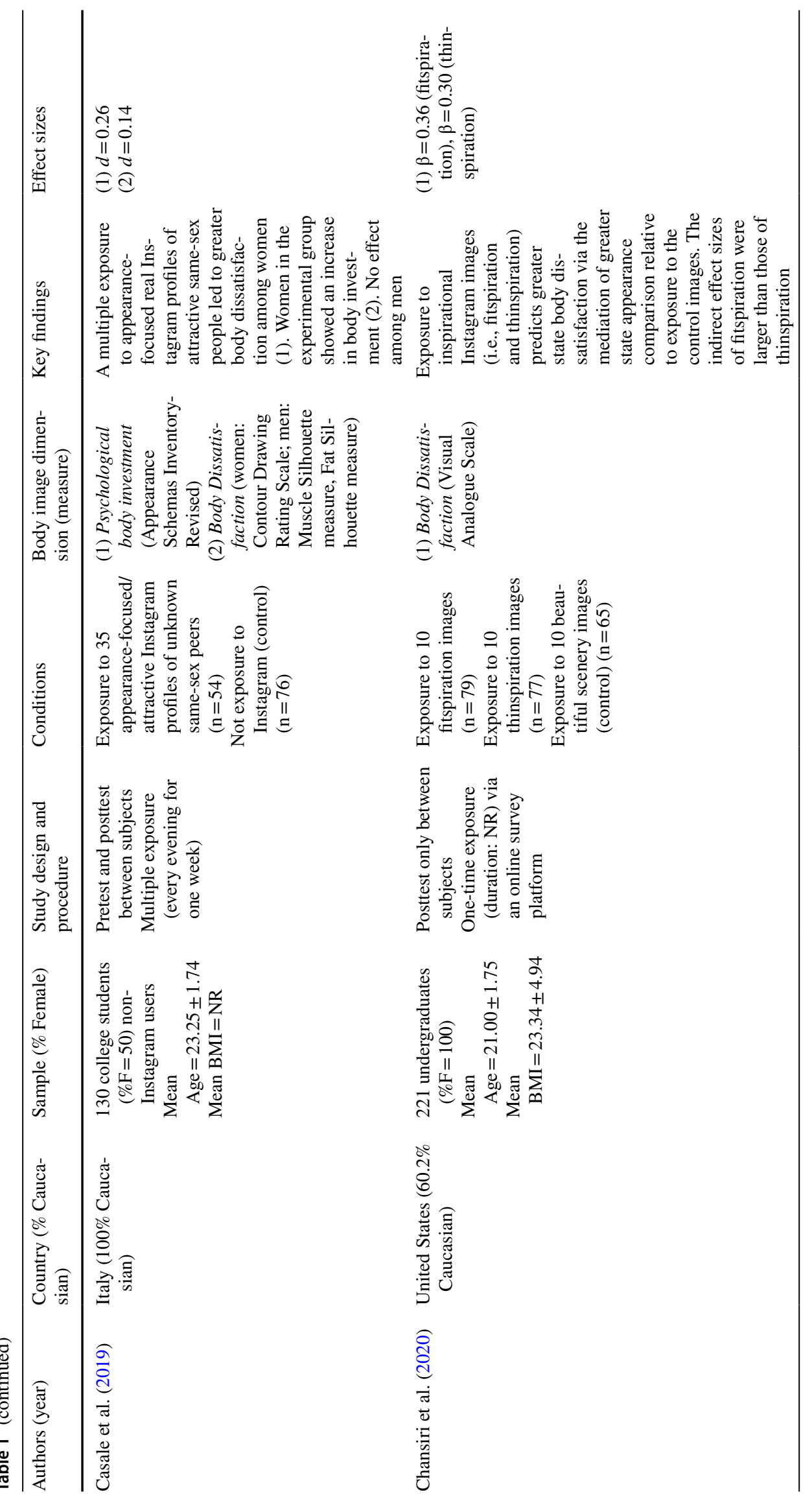




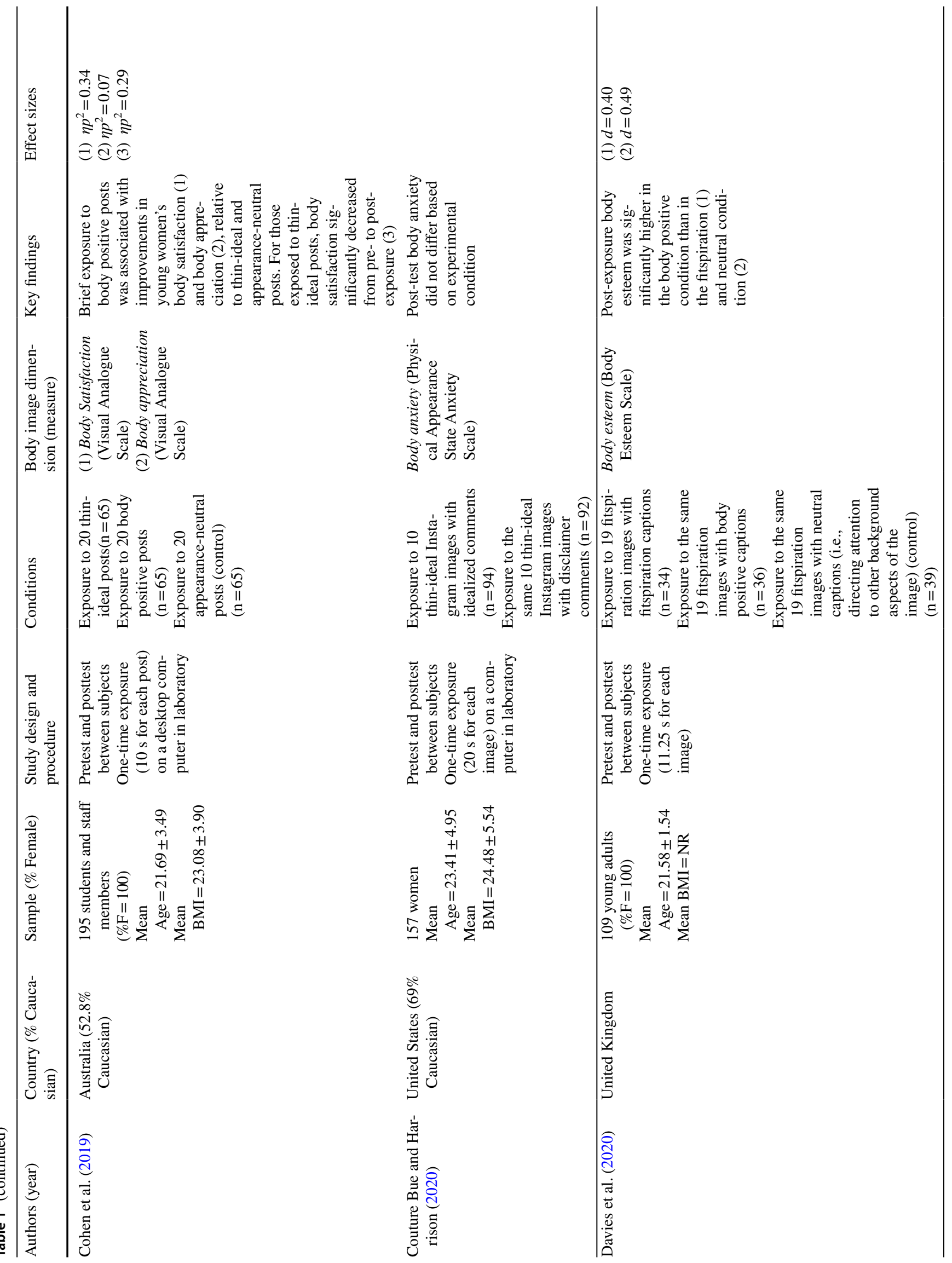




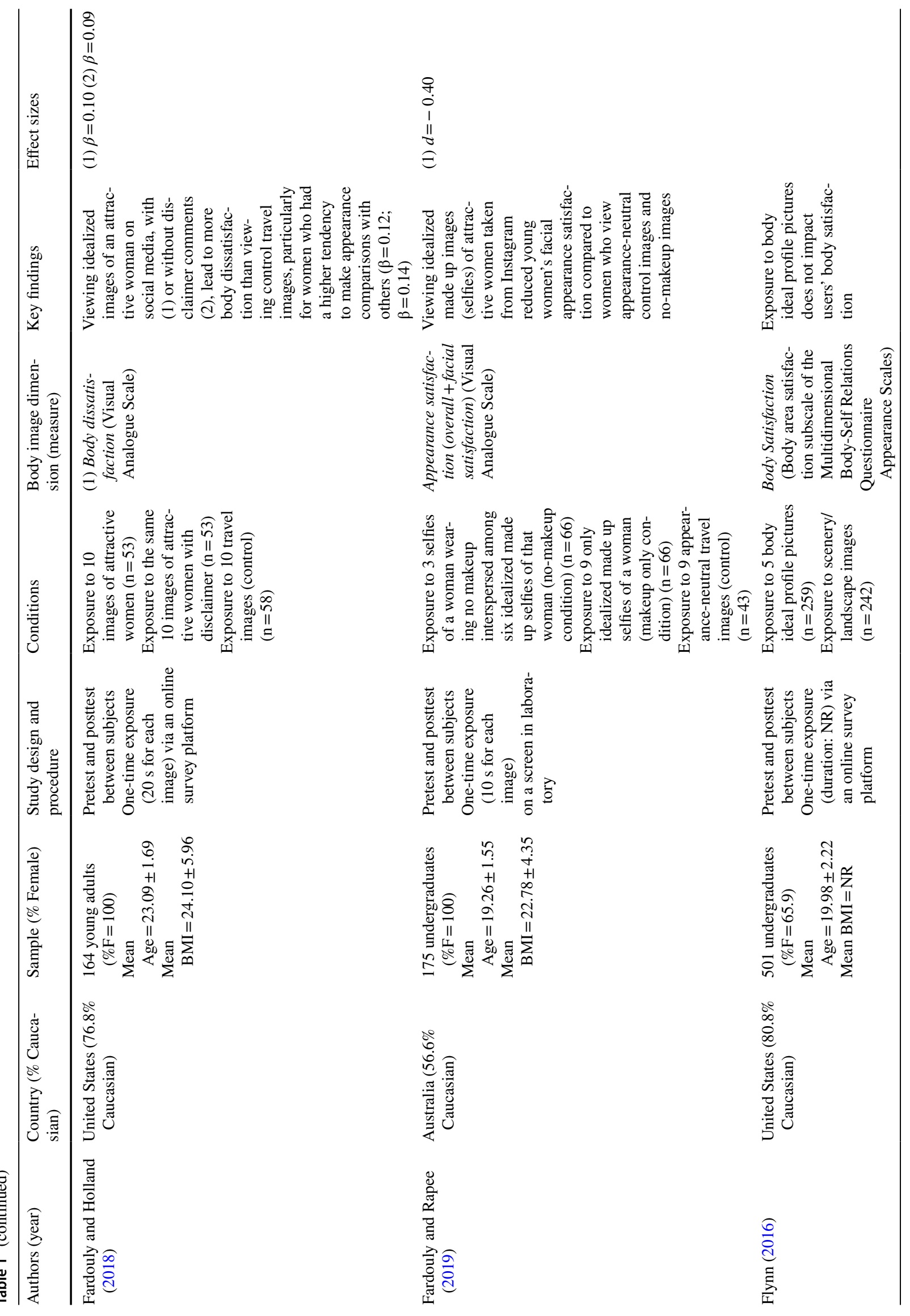




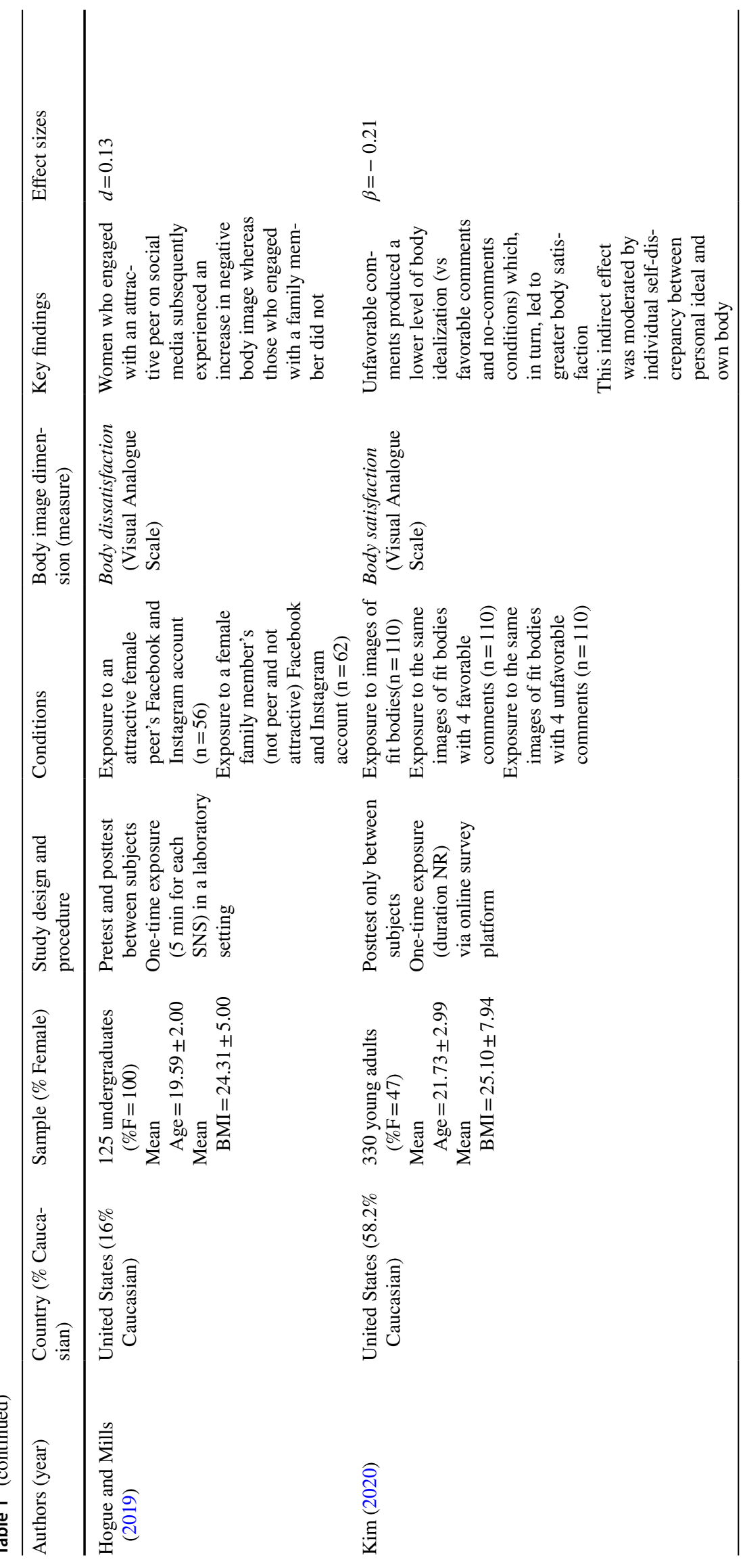




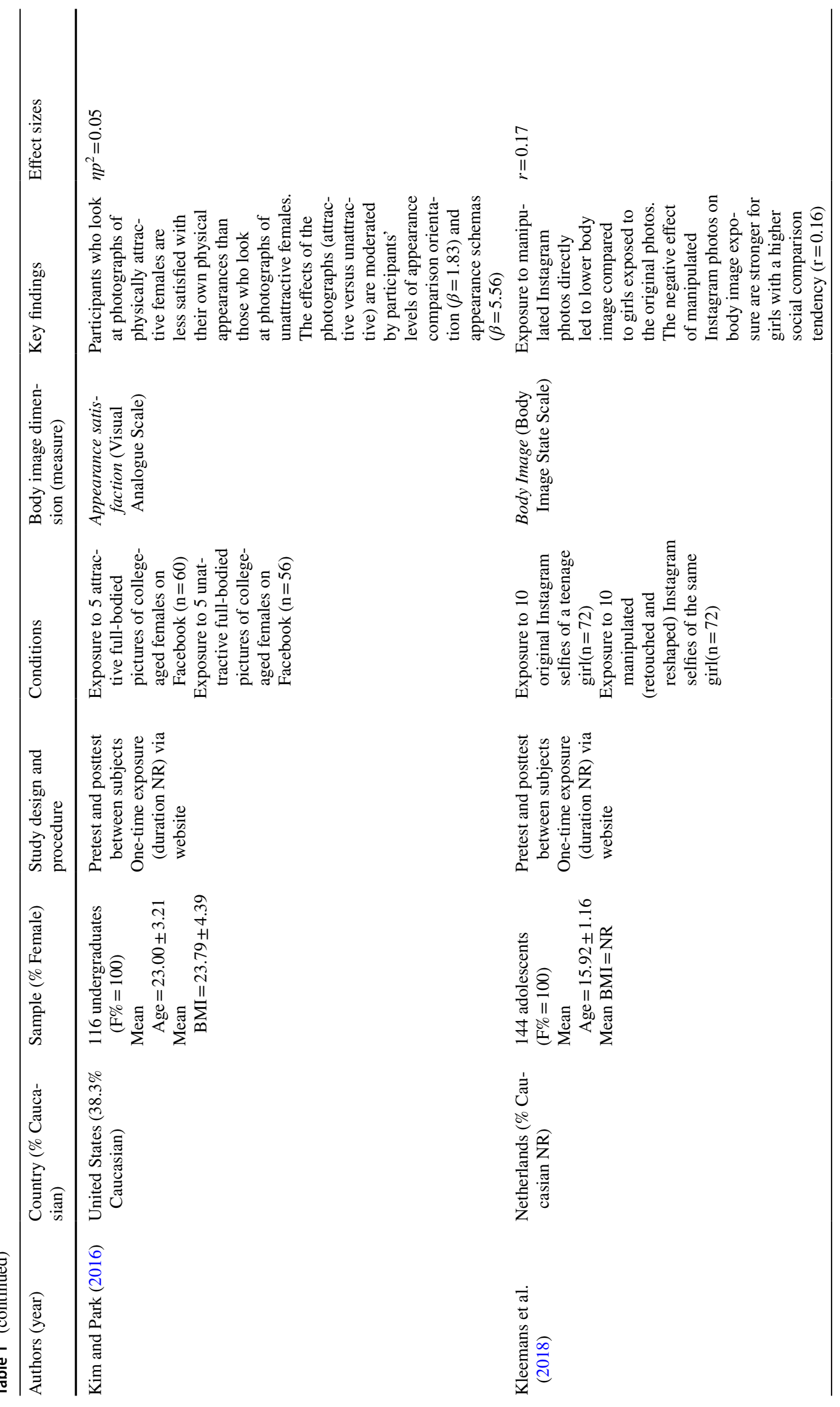




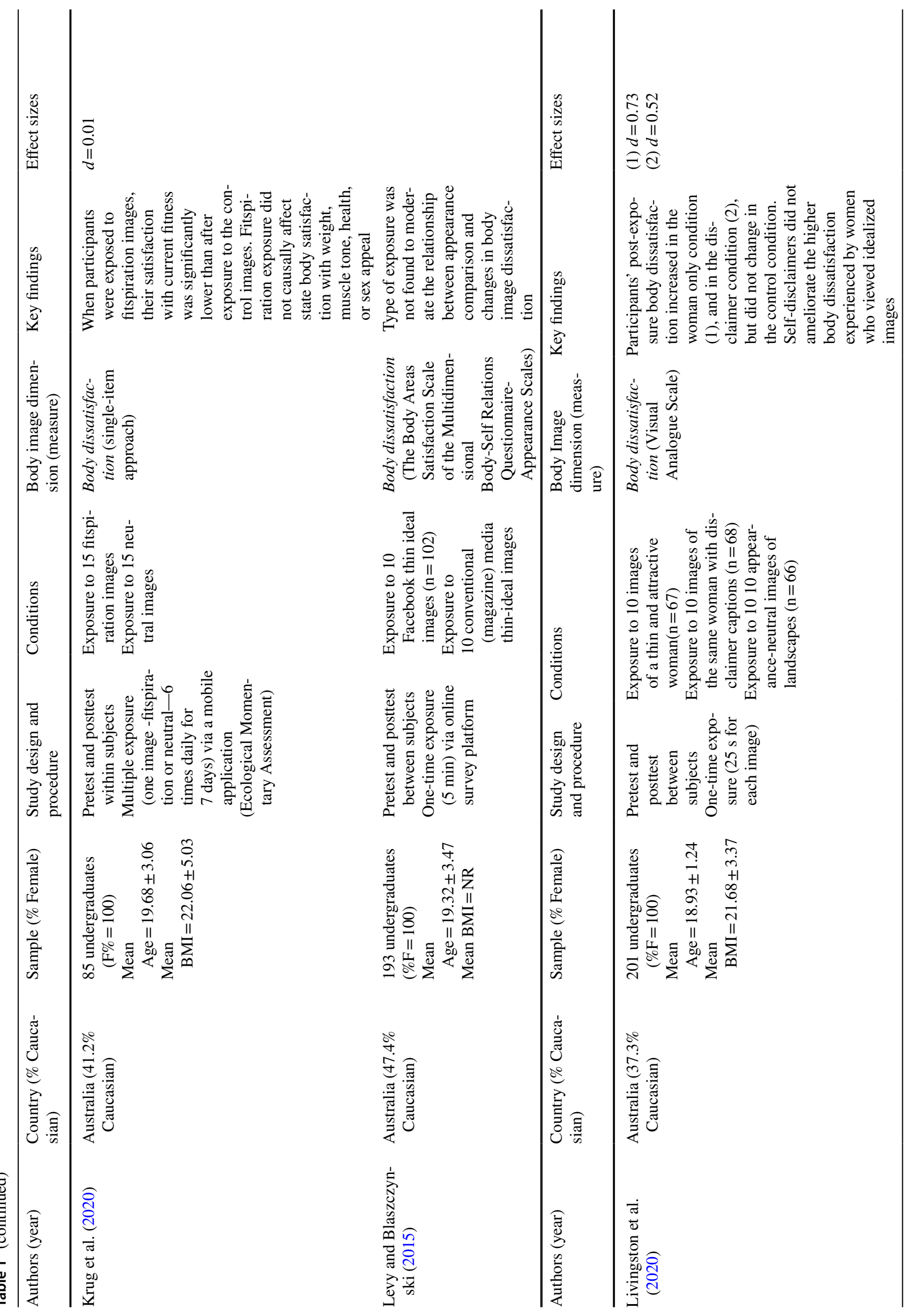




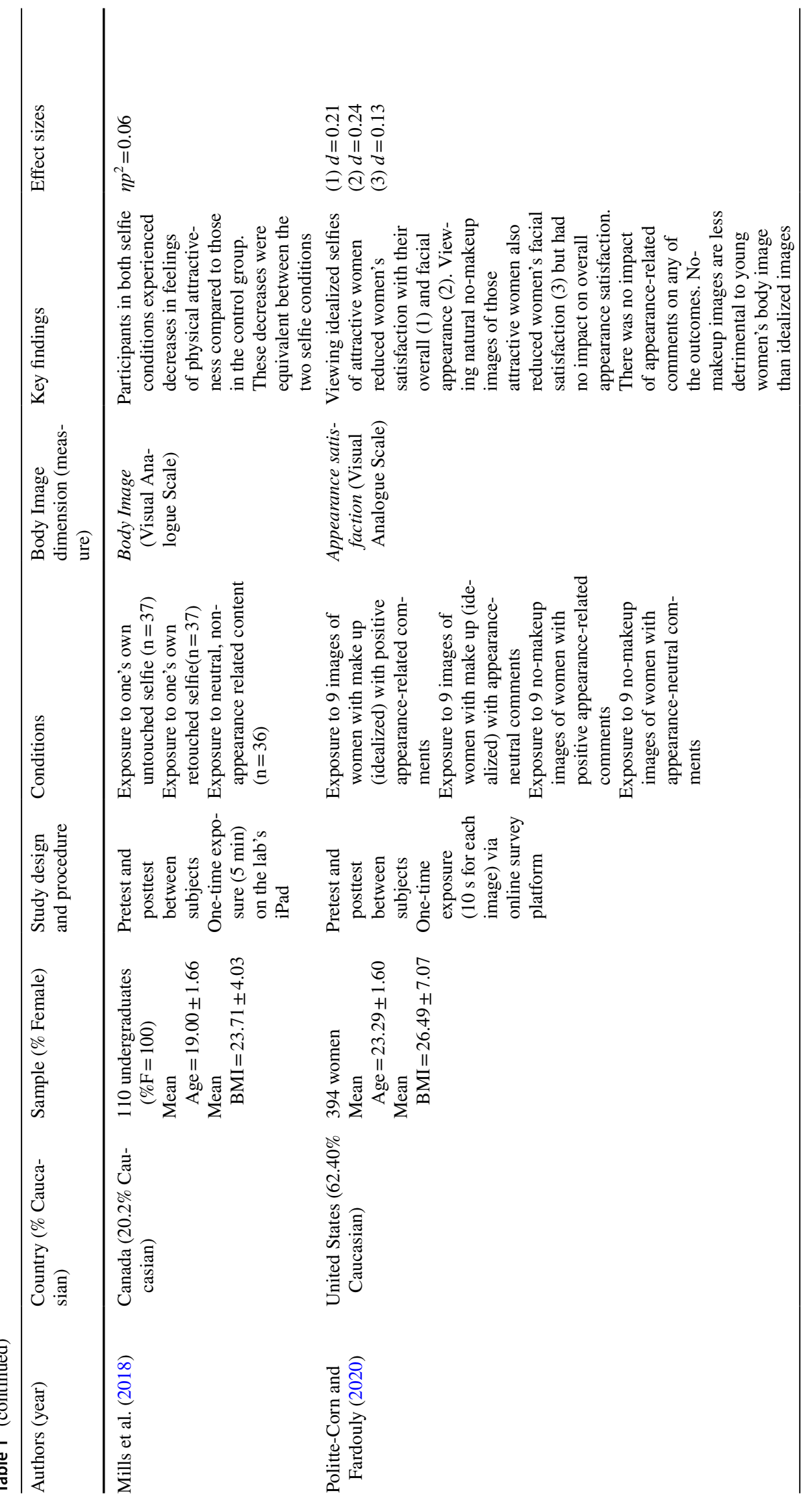




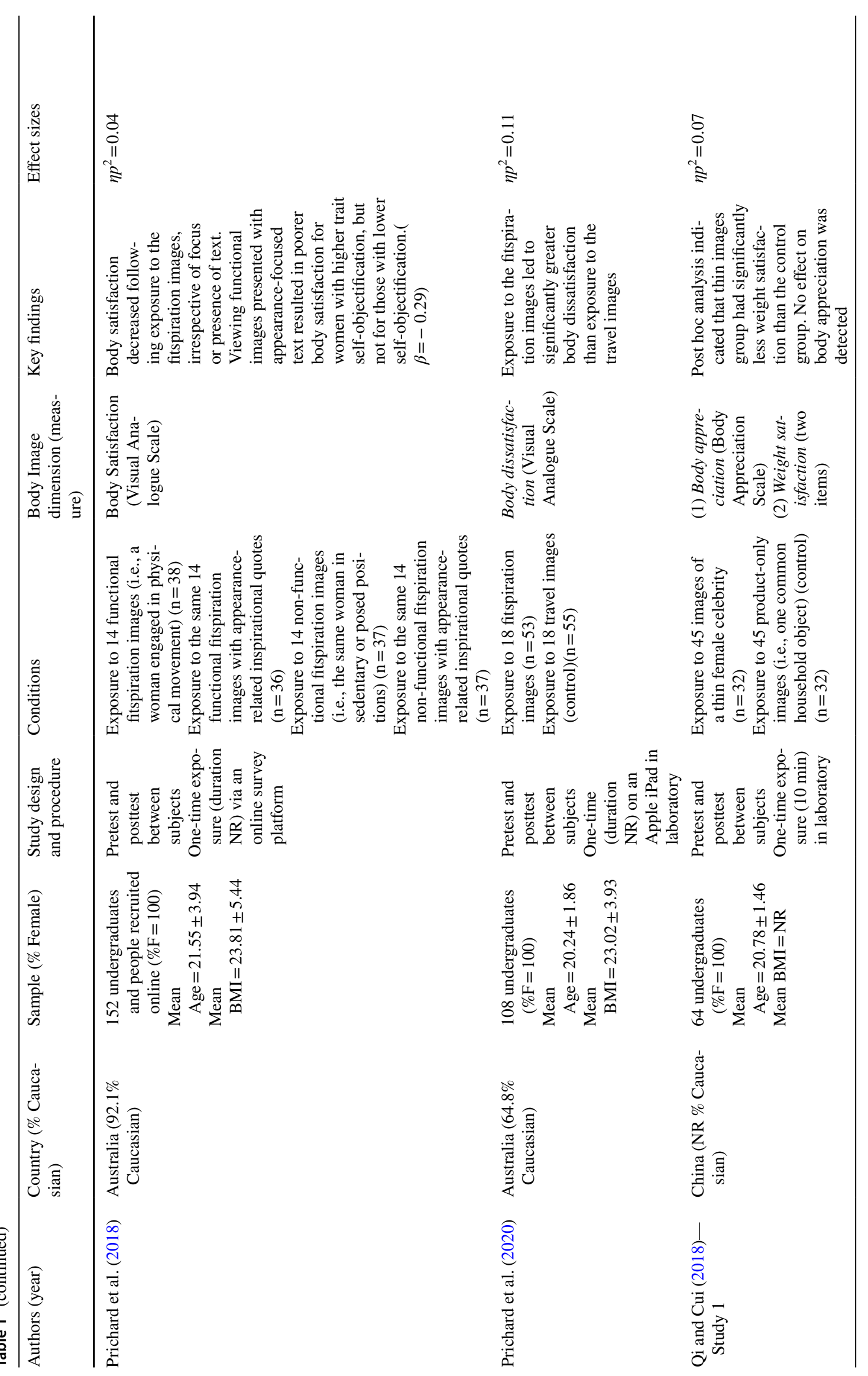




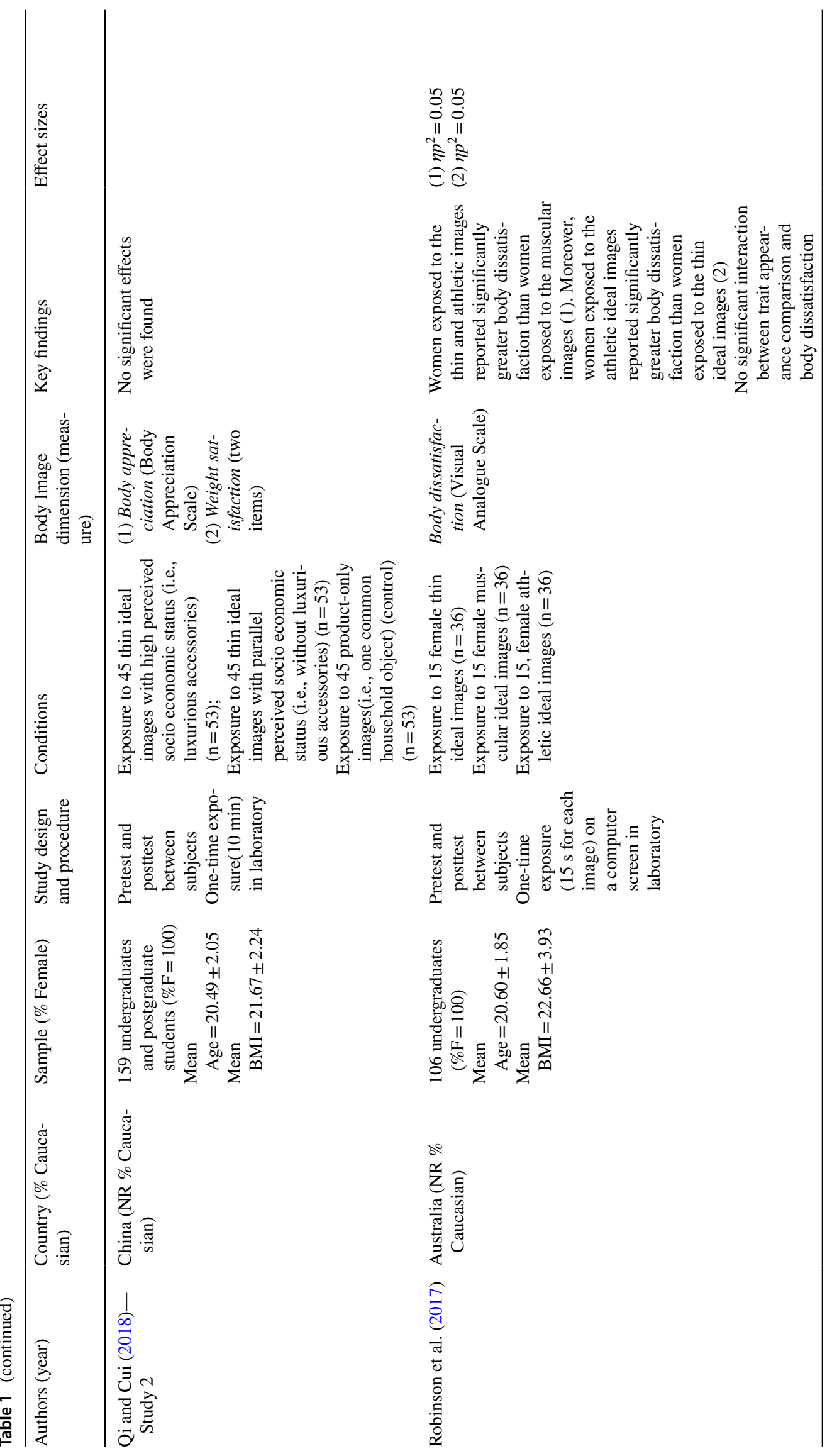




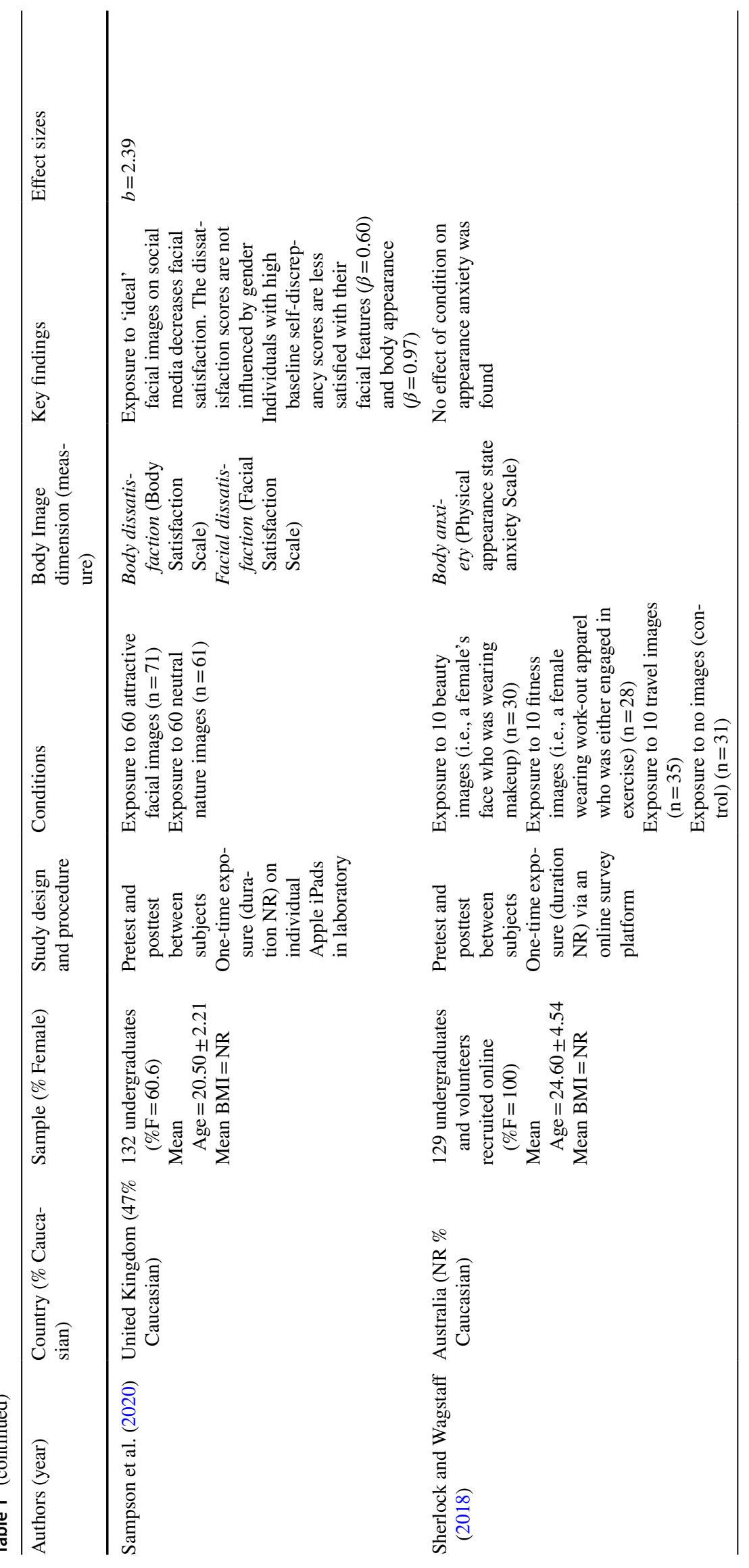




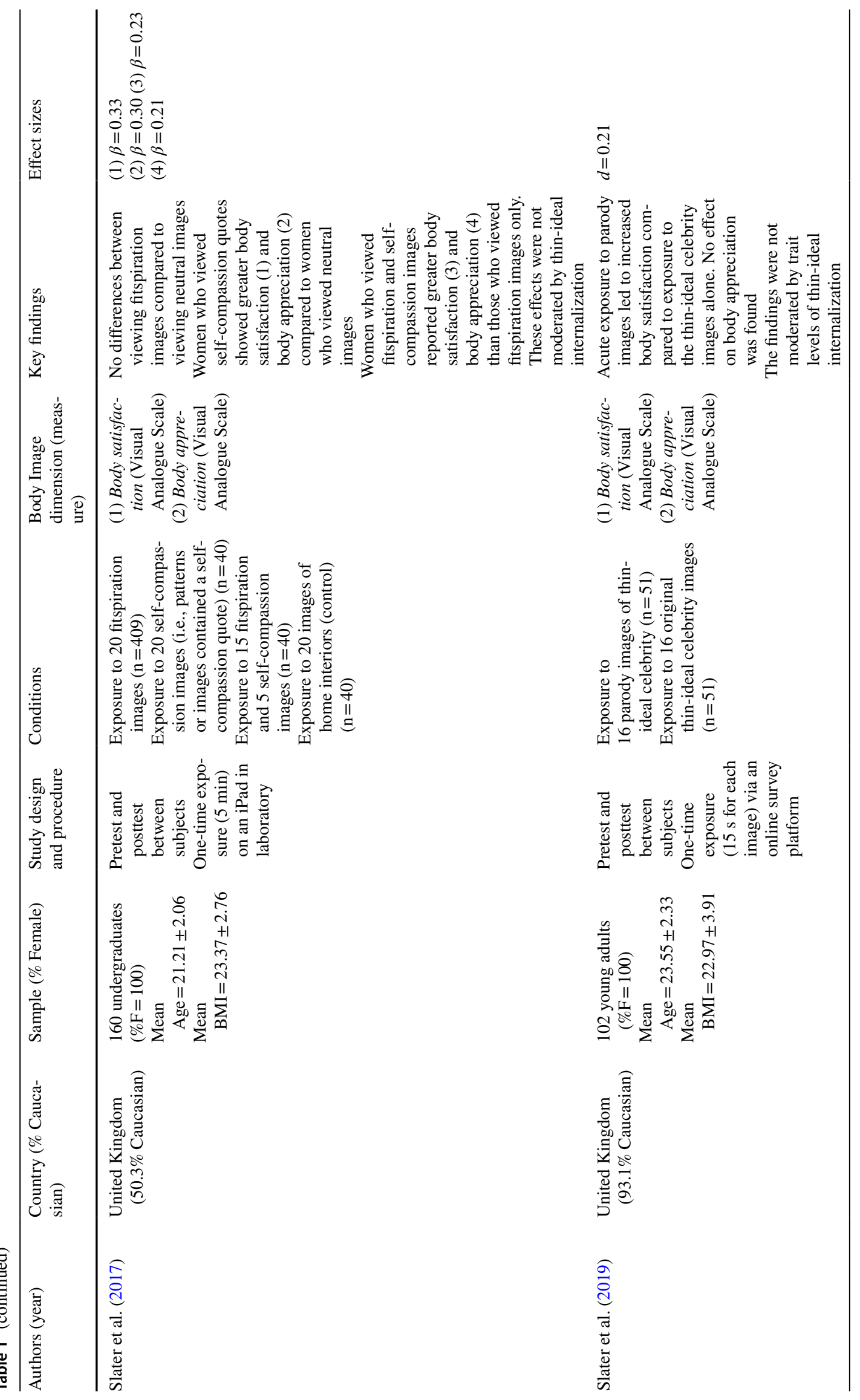




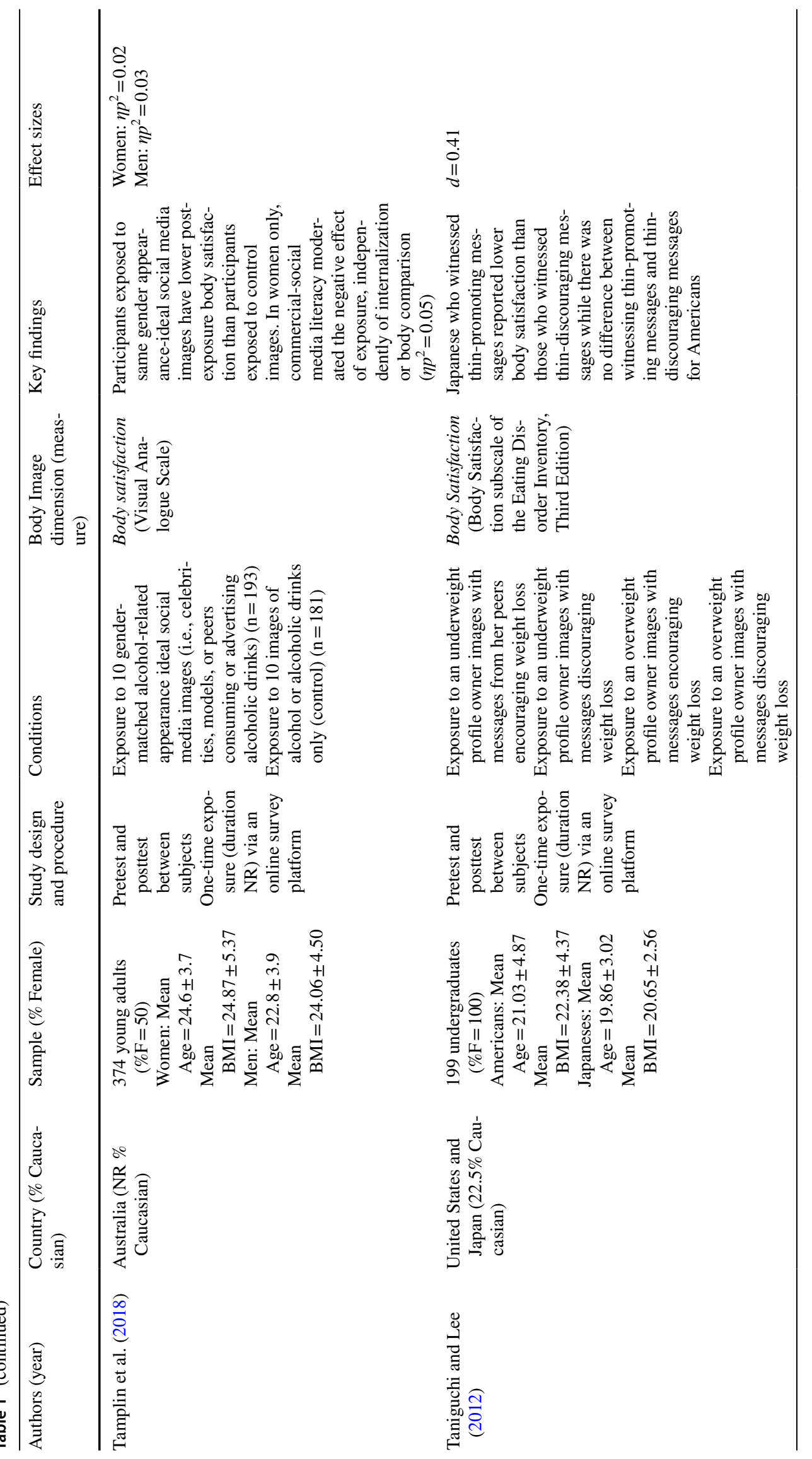




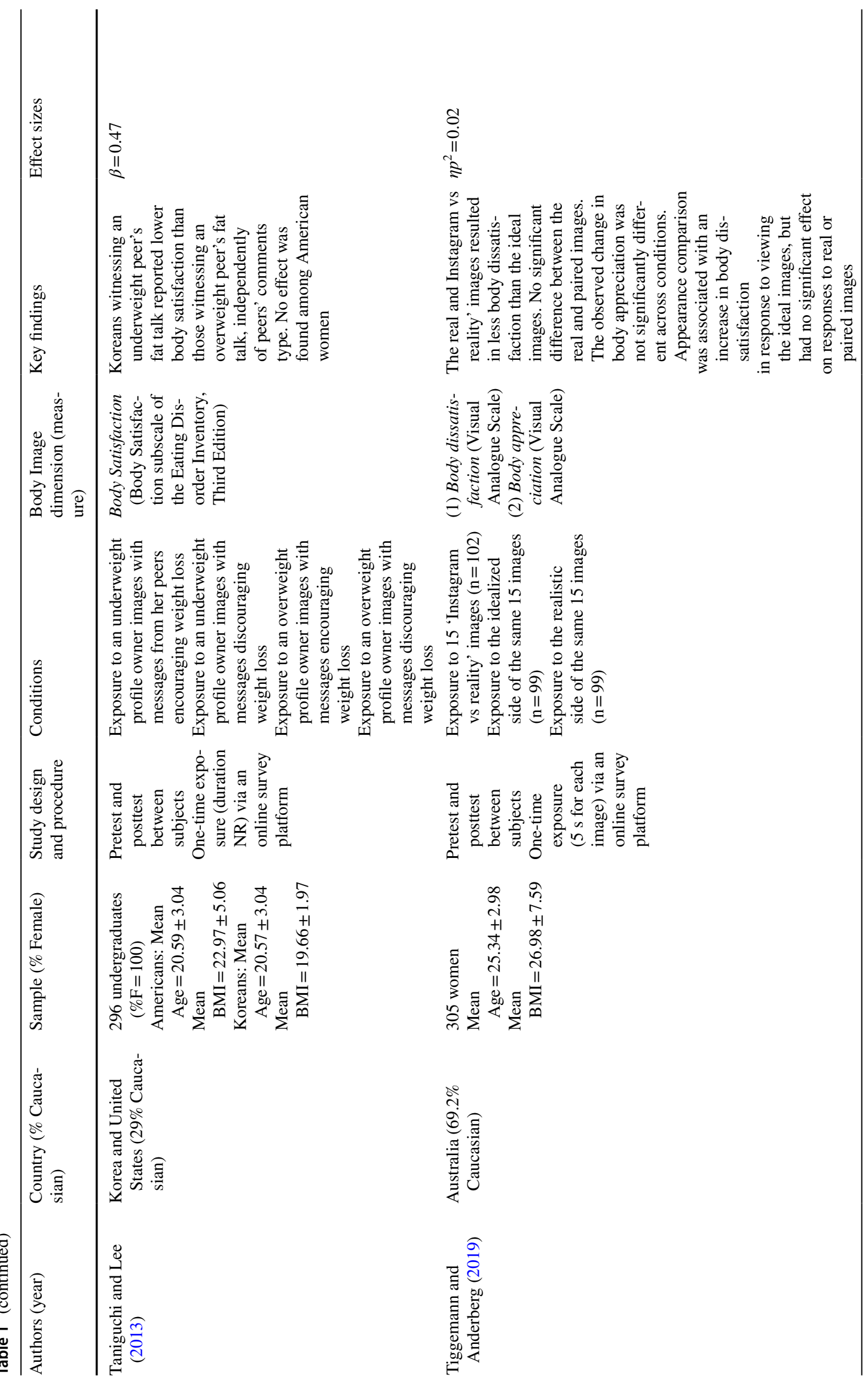




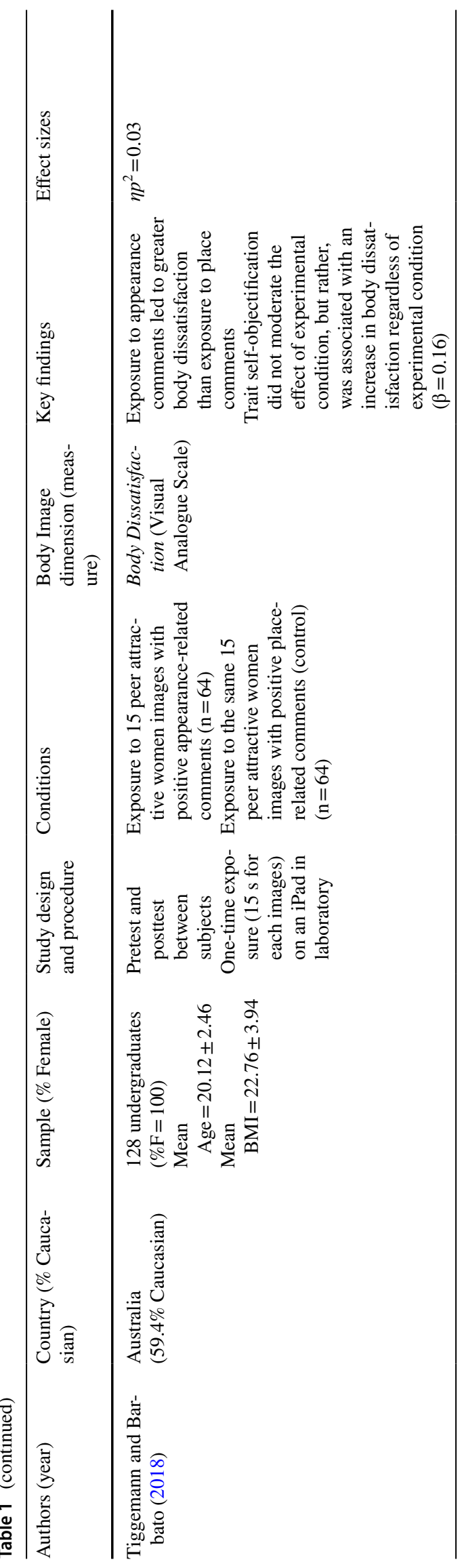




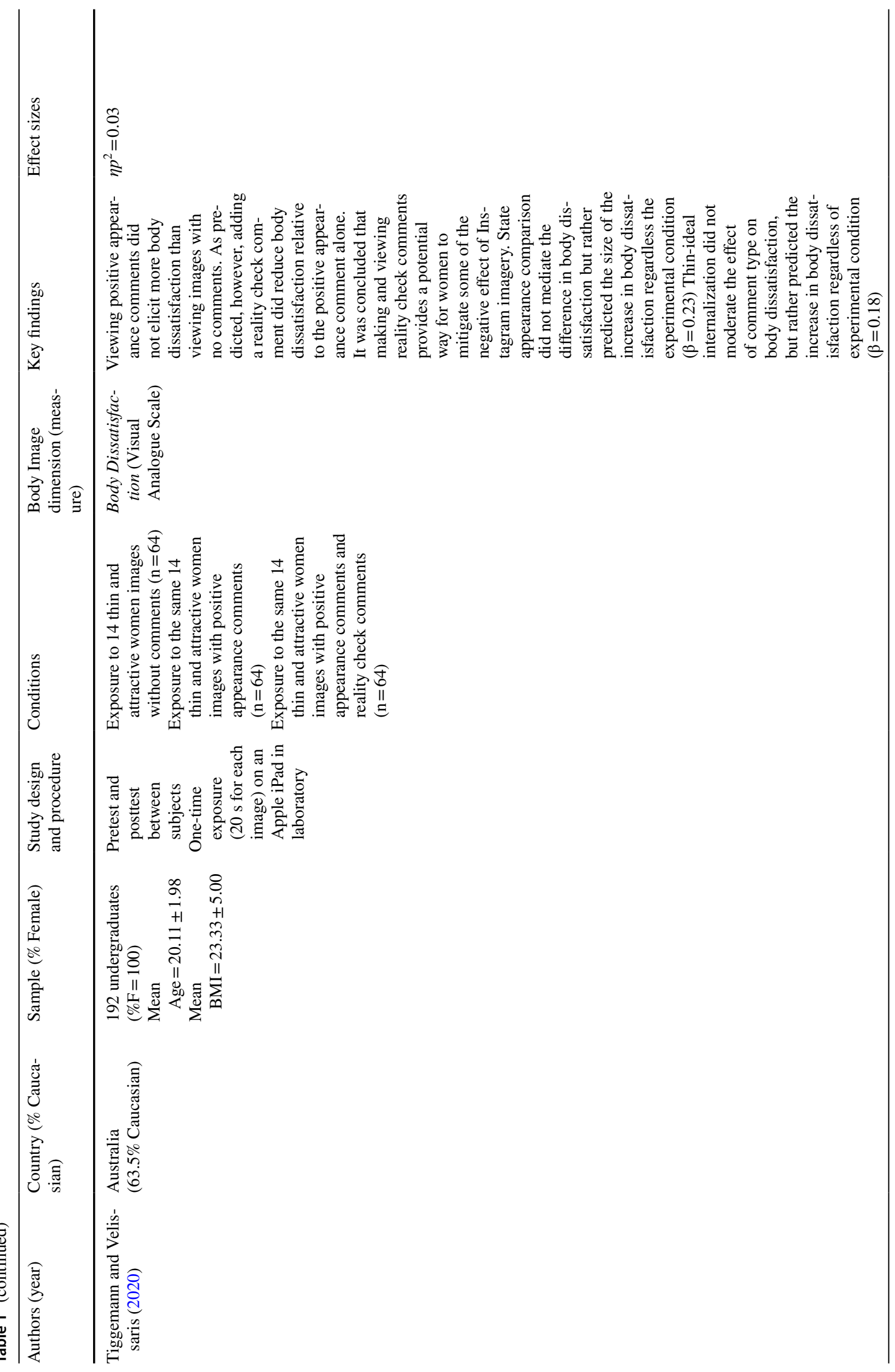




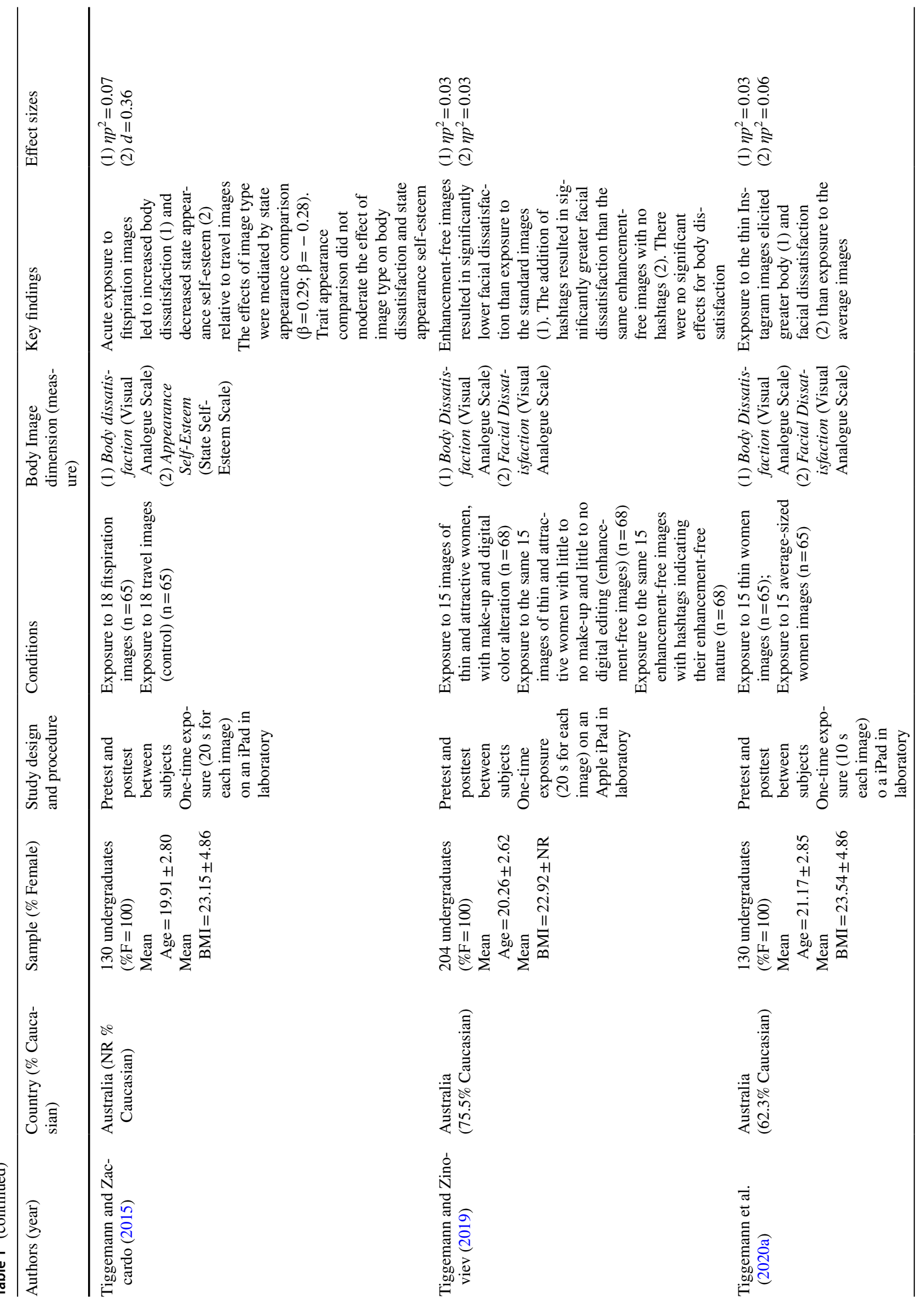




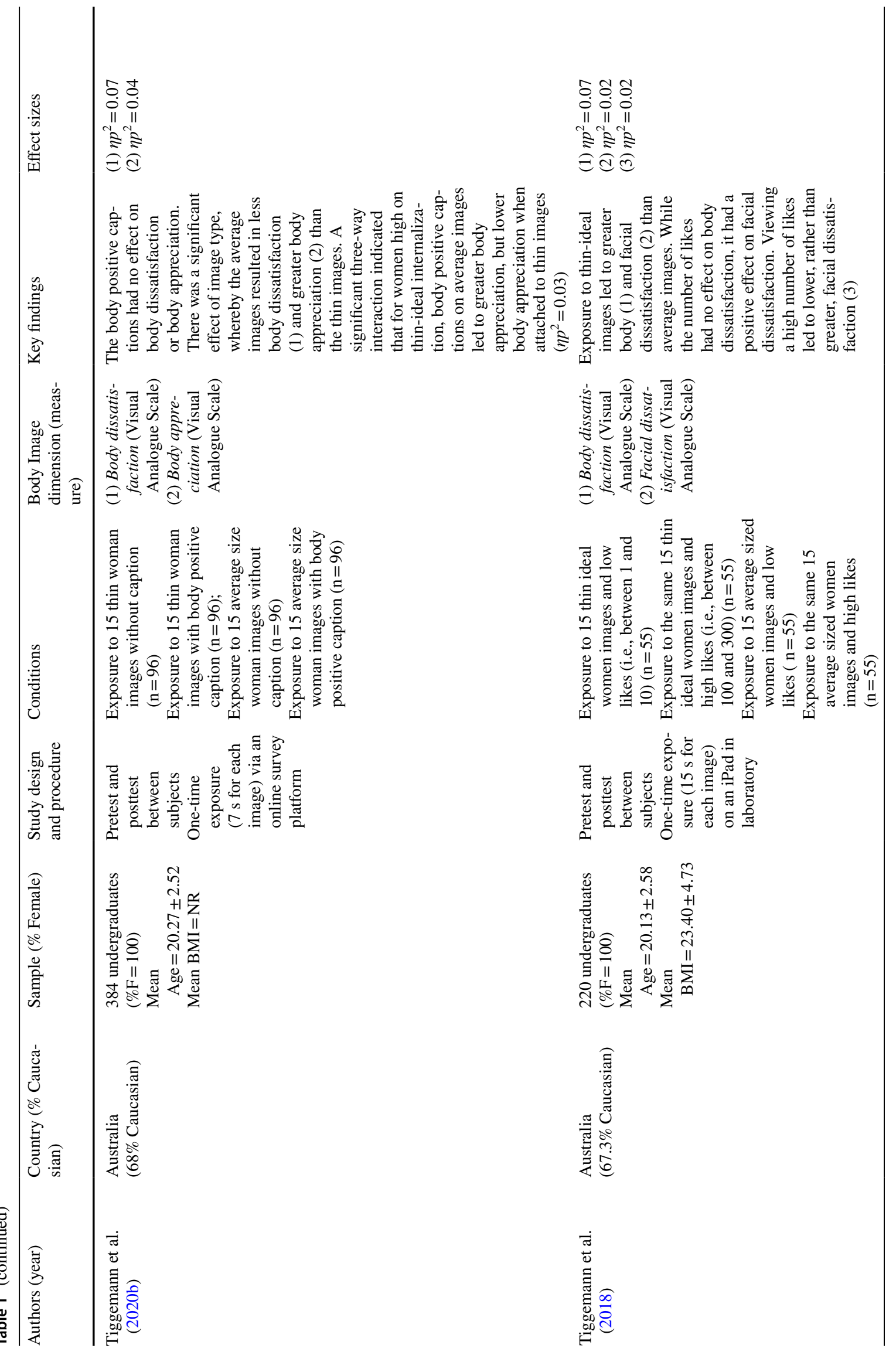




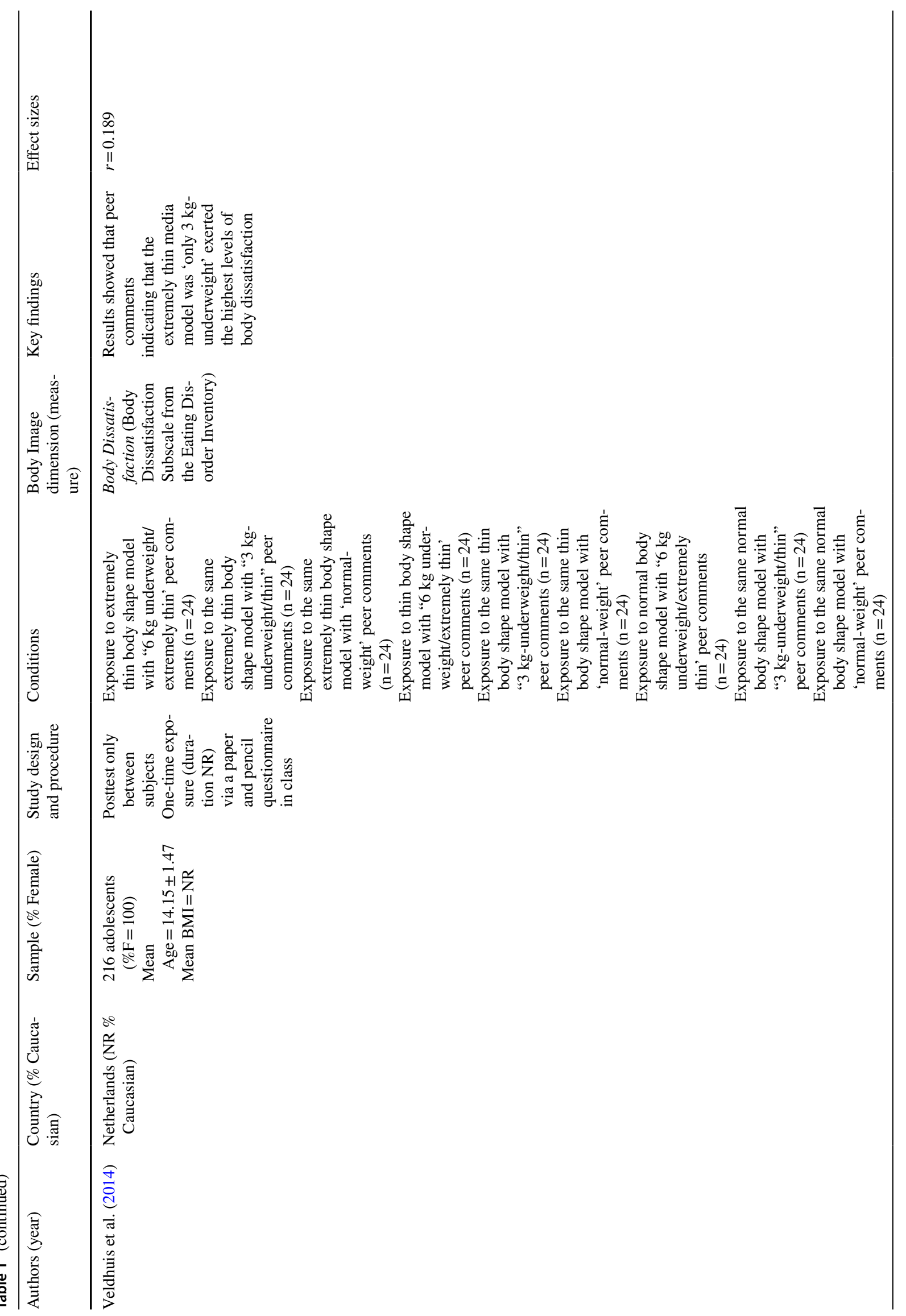




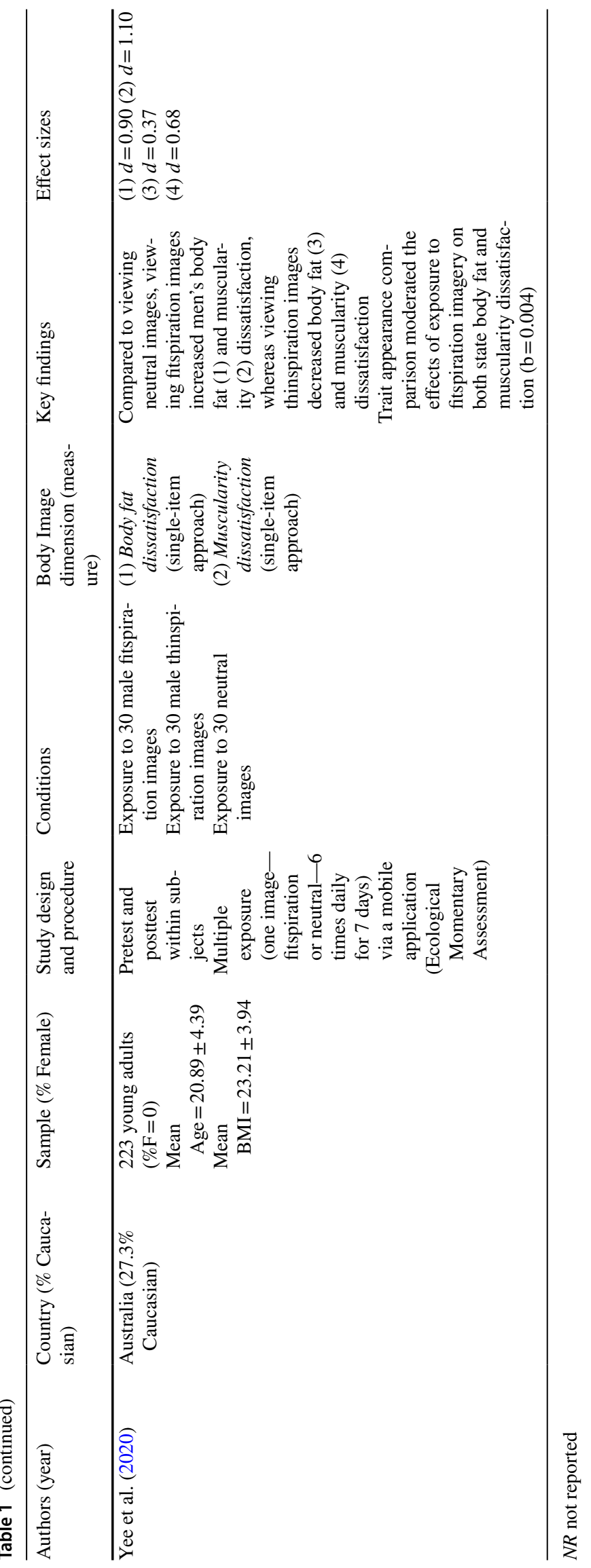


if the answers to the validity criteria questions $2,3,6$, and 7 did not indicate that the study was prominently strong. Lastly, a negative overall score was assigned if the majority (six or more) of the validity criteria questions were answered with a 'no' (American Dietetic Association, 2005; Myers et al., 2011).

\section{Results}

A systematic review was deemed to be more feasible and meaningful than a meta-analysis due to wide variability in experimental stimuli and psychological moderators used in the published research. Such a review is needed in order to clarify which types of images that people view every day on SNSs have a negative impact on body image and for which types of individuals, as well as to obtain some indications regarding the effectiveness of body positive images in reducing body dissatisfaction.

\section{Sample Characteristics}

Sample characteristics of the studies included in the qualitative synthesis can be found in Table 1. Studies were published between 2012 and 2020. The half of the studies were conducted on Australian samples $(n=22)$ the remaining studies were conducted on samples from United States $(n=10)$, United Kingdom $(n=4)$, Netherlands $(n=2)$, China $(n=2)$, Canada $(n=1)$, Italy $(n=1)$, Japan $(n=1)$, Korea $(n=1)$, and Saudi Arabia $(n=1)$. Thirty-six studies recruited women samples, one study used a male sample and the remaining six used gender-mixed samples. Twentyeight studies were conducted on undergraduate students, two studies on adolescents, and the remaining studies collected data from samples of young adults recruited on SNSs $(n=5)$, other websites $(n=1)$, and via Amazon Mechanical Turk (MTurk; $n=5$ ); two studies purposively sampled participants from active Instagram users. MTurk was chosen to recruit a more general and diverse sample not limited the 18-24 demographic typical of undergraduate students (Buhrmester et al., 2011).

The total sample consists of 8637 participants $(\% F=89.56$; mean age $=21.58 \pm 1.78$; range: 14.15-25.34 years old). Their mean BMI was 22.43 $(S D=1.99)$, which is in the "normal" weight range (Garrow \& Webster, 1984). The $48.52 \%$ of the participants selfidentified as Caucasian.

\section{Types of Experimental Design}

The majority of studies $(n=36)$ assessed the experimental effect using between subject, pretest and posttest designs; four studies conducted a between subject, posttest only design, whereas three studies used within subject, pretest and posttest designs. In pretest and posttest between subject studies, participants complete assessments of body imagerelated constructs, and then they are randomly assigned to different conditions. In the majority of studies $(n=32)$ participants were asked to view images taken from Instagram or Facebook depicting one or more idealized bodies (e.g., attractive, thin, fit; experimental condition) or images that are considered appearance-neutral (e.g., travel; control condition). Four studies (Brown \& Tiggemann, 2020; Cohen et al., 2019; Davies et al., 2020; Tiggemann et al., 2020b) investigated the effect of viewing body positive images or captions compared to idealized or neutral images. Following the experimental manipulation, participants are asked to complete post-test measures of body image-related constructs. Three studies (Chansiri et al., 2020; Kim, 2020; Veldhuis et al., 2014) assessed the experimental effect of viewing idealized SNS images using post stimulus scores only. Finally, in pretest and posttest within subject studies (Alanazi et al., 2019; Krug et al., 2020; Yee et al., 2020) participants complete the baseline assessments of body imagerelated constructs, and then they are randomly exposed to all the different conditions (i.e., idealized and control images). After viewing each image, the participants completed posttest measures of body image-related constructs.

Generally, the included studies investigated the effect of brief (one-time) exposure to SNSs images on body image yielding two measurement occasions (i.e., before and immediately after the experimental manipulation). The time exposure ranged from one to $10 \mathrm{~min}$. One study (Casale et al., 2019) considered a multiple exposure to Instagram attractive images for one week. Two studies (Krug et al., 2020; Yee et al., 2020) have experimentally examined the micro-longitudinal effects of viewing images on SNSs on body image using an Ecological Momentary Assessment (EMA) procedure for a 7-day period. EMA provides researchers access to the study of behavior in its natural context, whereas the majority of included studies were conducted in artificial settings (i.e., images were showed on a screen in laboratory or via online survey platforms).

\section{Types of SNSs Images Used}

Two different categories of SNSs images were used as experimental stimuli in the studies included in the present systematic review: (i) beauty ideal/idealized images, (ii) body positive images. All the images were taken from public Instagram, Facebook, Tumblr, WeChat profiles. Idealized images depict three main beauty ideals: attractive, thin and fit. It is important to note that even though the type of experimental stimulus from each study can be organized into these categories, each study had slight variations in how the images were presented for each category. 
For example, there were selfies and photos taken by others, images of peers and images of celebrities, full body shots, and shots of the person's face. Moreover, in some studies pictures were accompanied by captions/messages/ quotes (e.g., disclaimer captions-highlighting the unrealistic nature of social media content-, body positive messages, fitness inspirational quotes), or comments (e.g., idealized comments, critical comments), or hashtags, or the number of "likes" and followers. Generally, in the control condition participants were exposed to view appearance-neutral images-e.g., travel, landscapes, and architecture-(in 13 studies of the 43 included) or average size/overweight/unattractive bodies (in 8 studies of the 43 included). Three studies (Kleemans et al., 2018; Mills et al., 2018; Tiggemann \& Zinoviev, 2019) used enhancement-free images (i.e., without filters and digital alteration), and three studies (Fardouly \& Rapee, 2019; Politte-Corn \& Fardouly, 2020; Tiggemann \& Anderberg, 2019) used realistic representation of bodies (i.e., without make-up, showing cellulite or rolls of fat in a less flattering posture with less flattering lighting). Slater et al. (2019) used parody images of thin-ideal celebrity Instagram posts. In two studies (Casale et al., 2019; Sherlock \& Wagstaff, 2018), participants in the control condition were not exposed to SNS images.

\section{Attractive Beauty Ideal Images}

Altogether 19 of the 43 studies presented here exposed their sample to attractive beauty ideal images. They comprise images of thin and attractive people taken from SNSs public profiles (mainly from Instagram) and rated highly attractive by the target population. Generally, the images were selfies, included only the target individual, and ranged from full body shots to close up shots of the person's face. Women are depicted with makeup, wearing relatively tight or revealing clothing, or two-piece swimsuit, whereas men are shirtless. Four studies (Kleemans et al., 2018; Mills et al., 2018; Sampson et al., 2020; Tiggemann \& Zinoviev, 2019) used explicitly manipulated photos (i.e., edited with effects and filters, and color alteration) where eye bags, wrinkles, and blemishes were removed, legs were reshaped to look thinner, and the waist was reshaped to look slimmer.

\section{Thin Beauty Ideal Images}

Thin beauty ideal images represent thin bodies for women and muscular bodies for men and were sourced from SNSs public profiles (mainly from Instagram) and rated thin by the target population. Altogether 19 of the 43 studies included exposed their participants to thin ideal images. Usually they included full-body shots of women with thin physiques either posing in bikinis, form-fitting fashion, and revealing outfits to emphasize their body shape. In four studies
(Alanazi et al., 2019; Chansiri et al., 2020; Taniguchi \& Lee, 2012, 2013; Veldhuis et al., 2014) thin ideal images demonstrated women having an extremely thin body (i.e., visibly low body mass index), and photos were taken from angles that visually emphasized the model's thinness, particularly in terms of the model's arms, waist, and the gap between her thighs. Only one study (Brichacek et al., 2018) was conducted on a sample composed by both men and women, in this case men were exposed to viewing muscular/lean bodies.

\section{Fit Ideal Beauty Images}

Altogether 10 of the 43 studies presented here exposed their sample to fit ideal images. They portrayed women/men with thin and toned bodies, posing in fitness clothing or engaging in exercise (e.g., running, squatting), showing visible muscular parts (e.g., abdominal muscle and upper arms). Images were sourced from public SNSs profiles (mainly from Instagram) using the search terms '\#fitspo' and '\#fitspiration'.

\section{Body Positive Images}

Four studies (of the 43 included) exposed their sample to body positive images or captions.

'Body positive' refers to rejecting unrealistic body ideals and encouraging women to accept and love their bodies at any shape and size. Body positive images showed conventional and unconventional bodies presented with their flaws and imperfections as unique characteristics. Captions needed to be positive in tone, and focused on sentiments such as loving your body, life is more important than your body, and everybody is unique. Usually, body positive posts were sourced from public Instagram accounts (e.g., @bodyposipanda), and tend to depict larger women proudly posting their unique bodies and quotes about body acceptance.

\section{Risk of Bias Within Studies}

Results of the quality assessment for each study are presented in Table 2. Overall, 40 were rated to be of high quality, two were rated to be of neutral quality and one was rated to be of negative quality. The majority of studies $(n=28)$ were conducted on undergraduates, and therefore there is a risk that samples were not representative of young adults in general. All but three of the studies (i.e., those that have used a posttest only between subject design) had comparable experimental conditions prior to the manipulation, and therefore the results can be assumed to be due to the effects of the independent variables and not to pre-existing differences on the dependent variable between the groups. Twenty-one studies did not report how they handled withdrawals or the response rate. The majority of studies $(n=26)$ 
blinded participants to the purpose of the study by providing a cover story or a general/vague research title, helping to reduce the likelihood of response bias (i.e., demand characteristics). All the studies except one (Alanazi et al., 2019) used valid and reliable measures of body image and performed appropriate statistical analyses. For 18 studies it was not possible to determine whether a funding bias existed since they did not indicate whether the research was funded.

\section{Main Effects of Beauty Ideal Images on Body Image Dimensions}

\section{Body Dissatisfaction}

Altogether, 38 studies examined the impact of beauty ideal images on body dissatisfaction (i.e., the evaluative component of body image, that is, satisfaction/dissatisfaction with the body). The majority of the studies $(n=26)$ used visual analogue scales to measure body dissatisfaction/satisfaction. One study (Casale et al., 2019) used the Contour Drawing Rating Scale (Thompson \& Gray, 1995) for women, and the Muscle Silhouette measure, and the Fat Silhouette measure (Frederick et al., 2007) for men. Two studies (Flynn, 2016; Levy \& Blaszczynski, 2015) used the Body Areas Satisfaction Scale of the Multidimensional Body-Self Relations Questionnaire-Appearance Scales (Cash, 2000). Sampson et al. (2020) used the Body Satisfaction Scale (Slade et al., 1990), whereas three studies (Taniguchi \& Lee, 2012, 2013; Veldhuis et al., 2014) used the Body Dissatisfaction Subscale from the Eating Disorder Inventory (Garner et al., 1983). Two studies (Brichacek et al., 2018; Kleemans et al., 2018) used the Body Image State Scale (Cash et al., 2002). Finally, two studies (Krug et al., 2020; Yee et al., 2020) adopted a single item approach (e.g., How do you feel about your level of body fat/level of muscularity right now?' on an 11-point scale $(0=$ extremely dissatisfied, $10=$ extremely satisfied), whereas Qi and Cui (2018) used two ad hoc items (i.e., participants indicated their current level of satisfaction and dissatisfaction (reverse-scored) with their weight on a 10 -point scale $(1=$ not at all satisfied, $10=$ very satisfied $)$.

Among women, with respect to an attractive beauty ideal images versus appearance neutral images (e.g., travel, landscapes) comparison, exposure to attractive and thin bodies increased body dissatisfaction (Fardouly \& Holland, 2018, $\beta=0.09$; Brown \& Tiggemann, 2016, $\eta p^{2}=0.04$; Brown $\&$ Tiggemann, 2020, $\eta p^{2}=0.04$; Livingston et al., 2020, $d=0.73$; Mills et al., 2018, $\eta p^{2}=0.06$; Sampson et al., 2020, $b=2.39$; Tamplin et al., 2018, $\eta p^{2}=0.02$ ) and facial dissatisfaction (Fardouly \& Rapee, 2019, $d=-0.40$ ) relative to travel/landscapes images. Contrarily, Flynn (2016) failed to find a significant effect of viewing body ideal profile pictures on users' body satisfaction. However, when compared to viewing unattractive women, the exposure to attractive women images resulted in lower appearance satisfaction (Kim \& Park, 2016, $\eta p^{2}=0.05$ ).

With respect to an attractive beauty ideal images versus non-exposure to Instagram images comparison, women exposed to real Instagram profiles of attractive women reported greater body dissatisfaction from pre-test to posttest (Casale et al., 2019, $d=0.26$ ), whereas no changes in body dissatisfaction occurred in the control condition. When exposure to attractive idealized images were compared to view realistic representation of bodies (i.e., without make up, showing cellulite or rolls of fat in a less flattering posture with less flattering lighting), viewing the ideal images reduced body satisfaction compared to viewing the real images (Tiggemann \& Anderberg, 2019, $\eta p^{2}=0.02$; Fardouly \& Rapee, 2019; Politte-Corn \& Fardouly, 2020, $d=0.21$ ). Similarly, exposure to the thin and attractive women with make-up and digital color alteration images resulted in significantly higher facial dissatisfaction than viewing enhancement-free images (Tiggemann \& Zinoviev, 2019, $\eta p^{2}=0.03$; Kleemans et al., 2018, $r=0.17$ ). However no significant differences were found in physical attractiveness feelings between participants exposed to one's own untouched selfie and participants exposed to one's own retouched selfie (Mills et al., 2018). Finally, Tiggemann and Barbato (2018) found that exposure to attractive women images with positive appearance-related comments led to greater body dissatisfaction than exposure to the same attractive women images with place comments $\left(\eta p^{2}=0.03\right)$. However, adding a reality check comment did reduce body dissatisfaction relative to the positive appearance comment alone (Tiggemann \& Velissaris, 2020, $\eta p^{2}=0.03$ ).

With respect to $a$ thin beauty ideal images versus appearance neutral images comparison, exposure to thinspiration images predicts greater state body dissatisfaction relative to exposure to the control images (Chansiri et al., 2020, $\beta=0.30$; Brichacek et al., 2018, $d=-0.37$; Cohen et al., 2019, $\eta p^{2}=0.29$; Qi \& Cui, 2018, $\eta p^{2}=0.07$ ). With respect to a thin beauty ideal images versus average size women images comparison, exposure to the thin Instagram images elicited greater body dissatisfaction (Tiggemann et al., 2020a, $\eta p^{2}=0.03$; Tiggemann et al., 2020b, $\eta p^{2}=0.07$; Tiggemann et al., 2018, $\eta p^{2}=0.07$ ) and facial dissatisfaction (Tiggemann et al., 2020a, $\eta p^{2}=0.06$; Tiggemann et al., $2018, \eta p^{2}=0.02$ ) than exposure to the average size bodies images. The same result was obtained comparing exposure to underweight bodies images to overweight bodies images (Taniguchi \& Lee, 2013, $\beta=0.47$ ). When exposure to thinideal celebrity images was compared to viewing parody images, acute exposure to parody images led to increased body satisfaction compared to exposure to the thin-ideal celebrity images alone (Slater et al., 2019, $d=0.21$ ).

With respect to a fit beauty ideal images versus appearance neutral images comparison, exposure to fitspiration 


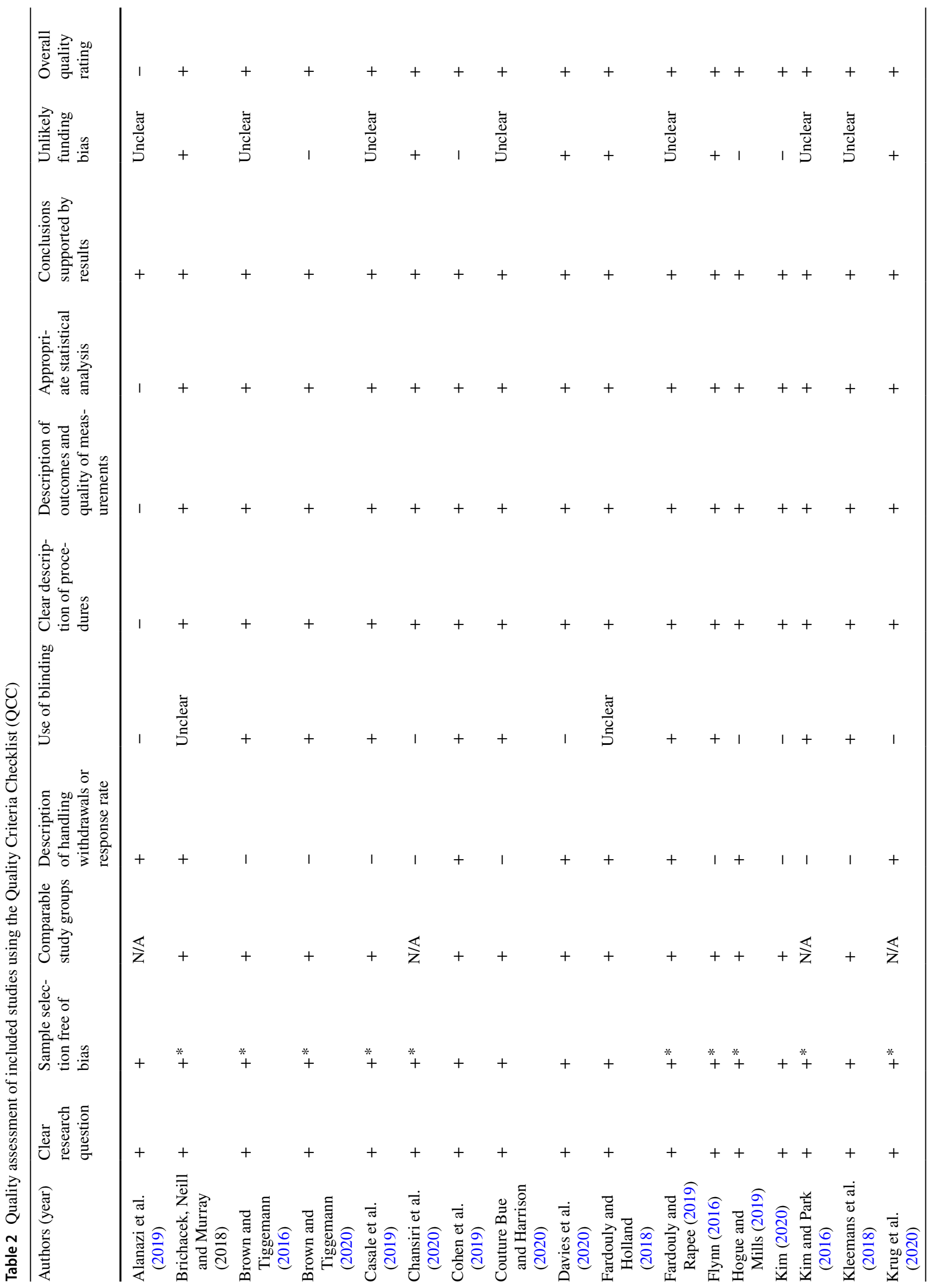


448

Adolescent Research Review (2022) 7:419-458

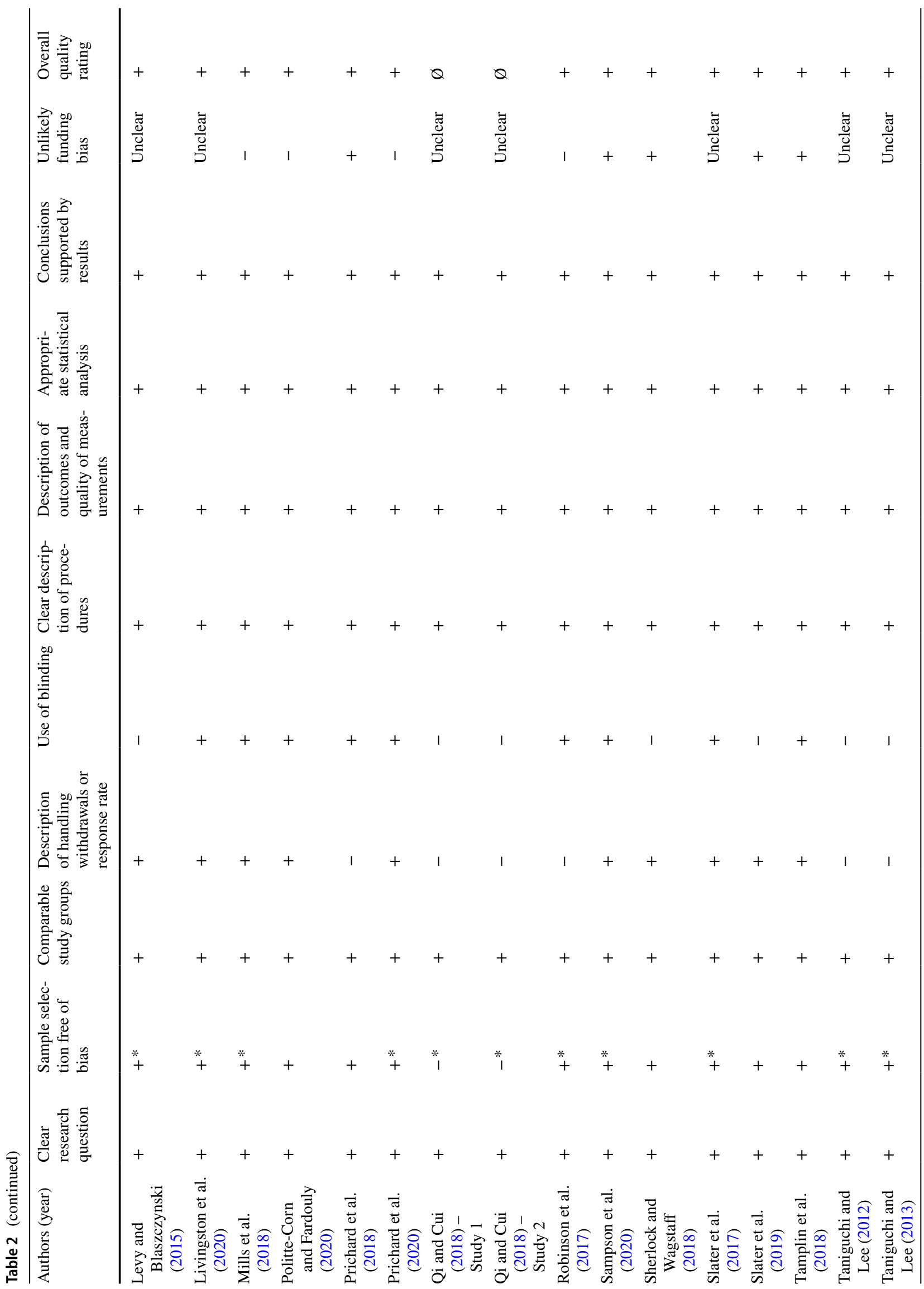

Springer 
Adolescent Research Review (2022) 7:419-458

449

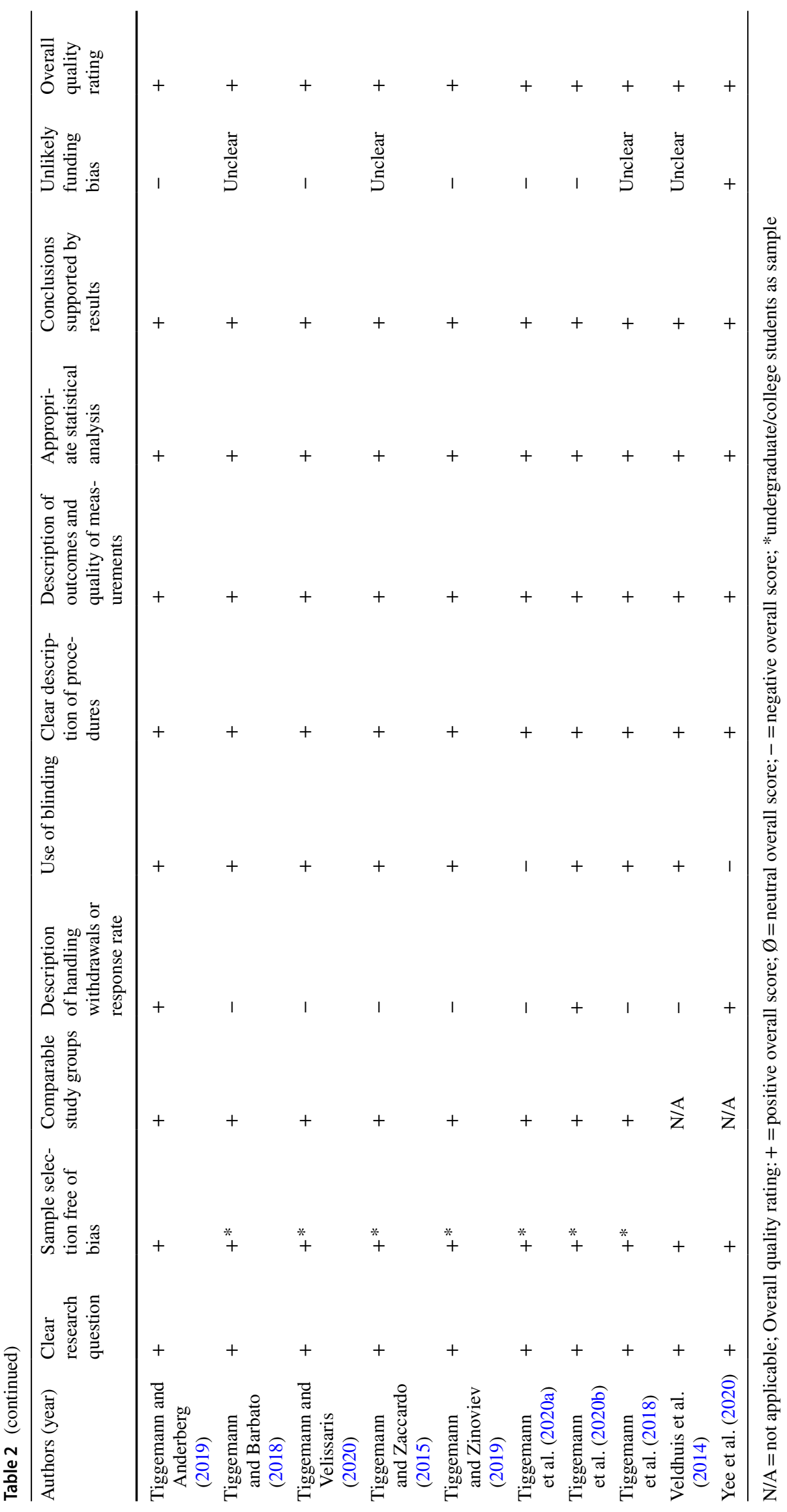

Springer 
images predicts greater body dissatisfaction relative to exposure to the control images (Chansiri et al., 2020, $\beta=0.36$; Prichard et al., 2020, $\eta p^{2}=0.11$; Tiggemann \& Zaccardo, $\left.2015, \eta p^{2}=0.07\right)$. However, Slater et al., (2017) found no difference in body satisfaction between viewing fitspiration images compared to viewing neutral images. Moreover, Krug et al. (2020) showed that multiple exposure to fitspiration images did not causally affect body satisfaction with weight, muscle tone, health, or sex appeal, whereas it negatively influenced only satisfaction with current fitness ( $d=0.01)$. Kim (2020) found that viewing fit ideal images with unfavorable comments to depicted body produced a lower level of body idealization (vs favorable comments and no-comments conditions) which, in turn, led to greater body satisfaction. Conversely, Prichard et al. (2018) found that body satisfaction decreased following exposure to the fitspiration images, irrespective of focus or presence of text $\left(\eta p^{2}=0.04\right)$. Finally, Robinson et al. (2017) found that women exposed to athletic ideal images reported greater body dissatisfaction than women exposed to the thin ideal images $\left(\eta p^{2}=0.05\right)$.

Among men, exposure to attractive facial images decreases facial satisfaction relative to exposure to neutral nature images (Sampson et al., 2020), as well as viewing muscular/attractive bodies resulted in significantly lower body satisfaction compared to viewing appearance-neutral images (Brichacek et al., 2018; Tamplin et al., 2018, $\eta p^{2}=0.03$ ), whereas Casale et al. (2019) found no effect of the multiple exposure to attractive Instagram profiles on body dissatisfaction among men. Yee et al. (2020) found that compared to viewing neutral images, viewing fitspiration images increased men's body fat $(d=0.90)$ and muscularity dissatisfaction $(d=1.10)$, whereas viewing thinspiration images decreased body fat $(d=0.37)$ and muscularity dissatisfaction $(d=0.68)$.

\section{Body Appreciation}

Altogether, 8 studies examined the impact of beauty ideal images on body appreciation (i.e., appreciating the features, functionality, and health of the body rather than focusing solely on its appearance (Tylka \& Wood-Barcalow, 2015, p. 123). The majority of studies $(n=6)$ used the visual analogue scale developed by Slater et al. (2017). It consists of three items taken from the Body Appreciation Scale (Avalos et al., 2005) and adapted into a state measure. One study (Cohen et al., 2019) used the State Body Appreciation Scale-2 (SBAS-2; Homan, 2016) presented as a visual analogue scale, whereas Qi and Cui (2018) used the Body Appreciation Scale-2 (BAS-2; Tylka \& Wood-Barcalow, 2015). All the studies were conducted on female samples.

With respect to an attractive beauty ideal images versus appearance neutral images comparison, exposure to idealized images decreased body appreciation (Brown \& Tiggemann, 2020, $\left.\eta p^{2}=0.04\right)$. Body appreciation was found to decrease in response to viewing the ideal images, and to increase in response to viewing the real and paired images, however the observed change in body appreciation was not significantly different across conditions (Tiggemann \& Anderberg, 2019).

With respect to a thin beauty ideal images versus appearance neutral images comparison, no differences were found in body appreciation levels (Cohen et al., 2019; Qi \& Cui, 2018). The same result occurred when thin ideal celebrity images were compared with parody images (Slater et al., 2019). Conversely, Tiggemann et al. (2020b) found that body appreciation increased after viewing average size women images in comparison to viewing thin women.

With respect to a fit beauty ideal images versus appearance neutral images comparison, no differences were found in body appreciation levels (Slater et al., 2017). However, women who viewed self-compassion images together with fitspiration images reported greater body appreciation than those who viewed fitspiration images only (Slater et al., 2017, $\beta=0.21)$.

\section{Other Body Image-Related Outcomes}

Some of the studies included in this systematic review assessed also other body image-related outcomes, such as appearance self-esteem, psychological body investment and body anxiety. Casale et al. (2019) showed that a multiple exposure to appearance-focused real Instagram profiles of attractive same-sex people led to greater body investment among women $(d=0.14)$ but not among men. Tiggemann and Zaccardo (2015) found that acute exposure to fitspiration images led to decreased state appearance self-esteem $(d=0.36)$ relative to travel images among young women. Post-test body anxiety did not differ after the exposure to thin ideal women images with idealized comments vs disclaimer comments (Couture Bue \& Harrison, 2020). Similarly, viewing beauty and fitness images did not affect women's body anxiety compared to viewing neutral images or not viewing images (Sherlock \& Wagstaff, 2018).

\section{Main Effects of Body Positive Images on Body Image Dimensions}

Body satisfaction and appreciation in response to body positive images have been measured in four studies using visual analogue scales. The majority of studies investigated the effect of body positive captions attached to images, whereas only one study (Cohen et al., 2019) examined the effect of viewing body-positive Instagram posts on young women's body image. Two studies (Brown \& Tiggemann, 2020; Tiggemann et al., 2020b) found that the addition of 
body positive captions by attractive and thin women images does not serve to improve women's body image. Contrarily, Davies et al. (2020) showed that post-exposure body esteem was significantly higher among women exposed to fitspiration images with body captions than among women who viewed fitspiration images with fitspiration captions or with neutral captions $(d=0.40, d=0.49)$. Brief exposure to body positive posts (i.e., images and quotes) was associated with improvements in young women's body satisfaction $\left(\eta p^{2}=0.34\right)$ and body appreciation $\left(\eta p^{2}=0.07\right)$, relative to thin-ideal and appearance-neutral posts (Cohen et al., 2019).

\section{Mediators/Moderators of the Effects of SNSs Images on Body Image Dimensions}

\section{Appearance and Social Comparison Tendency}

Four studies (Brown \& Tiggemann, 2016, 2020; Chansiri et al., 2020; Tiggemann \& Zaccardo, 2015) found that state appearance comparison mediated the effect of experimental condition (attractive/thin ideal or fit ideal images vs neutral images) on body image (i.e., body dissatisfaction, body appreciation, appearance self-esteem). Effect sizes ranged from $\beta=0.05$ to $\beta=0.36$. One study (Tiggemann \& Velissaris, 2020) failed to find a mediating role of state appearance comparison in the relationship between exposure to thin and attractive women images on body dissatisfaction but rather predicted the size of the increase in body dissatisfaction regardless the experimental condition $(\beta=0.23)$.

Eight studies (Brown \& Tiggemann, 2020; Fardouly \& Holland, 2018; Kim \& Park, 2016; Kleemans et al., 2018; Robinson et al., 2017; Tiggemann \& Anderberg, 2019; Tiggemann \& Zaccardo, 2015; Yee et al., 2020) examined trait appearance comparison tendency as a potential moderator of the effect of image type. Two studies found that trait appearance comparison did not moderate the relationship between experimental condition and body dissatisfaction among women. Specifically, the exposure to fit and athletic images led to increased body dissatisfaction relative to travel images independently by the trait appearance comparison tendency levels (Robinson et al., 2017; Tiggemann $\&$ Zaccardo, 2015). However, six studies did find that trait appearance comparison tendency moderated the relationship between image condition and body dissatisfaction. Therefore, viewing idealized images of attractive women on social media, led to more body dissatisfaction than viewing control images, particularly for women who had a higher tendency to make appearance comparisons with others (Fardouly \& Holland, 2018, $\beta=0.12, \beta=0.14$; Kim \& Park, 2016, $\beta=1.83$; Kleemans et al., 2018, $r=0.16$; Tiggemann \& Anderberg, 2019). Finally, Brown and Tiggemann (2020) found that trait appearance comparison moderated the effect of exposure to thin and attractive women images on women's body appreciation $(\beta=-0.11, \beta=-0.11, \beta=-0.10)$ and Yee et al. (2020) found that trait appearance comparison moderated the effects of exposure to fitspiration imagery on both state body fat and muscularity dissatisfaction $(b=0.004)$. among men.

\section{Self-objectification}

Only two studies examined trait self-objectification as a moderator between image condition and body satisfaction with inconsistent findings. Prichard et al. (2018) found that viewing fitspiration images presented with appearancefocused text resulted in poorer body satisfaction for women with higher trait self-objectification, but not for those with lower self-objectification $(\beta=-0.29)$. Tiggemann and Barbato (2018) showed that trait self-objectification did not moderate the effect of experimental condition (i.e., exposure to attractive women images with appearance comments vs with place comments), but rather was associated with an increase in body dissatisfaction regardless of experimental condition $(\beta=0.16)$.

\section{Thin-Ideal Internalization}

Results regarding the role of thin-ideal internalization as a moderator of the relationship between beauty ideal images and body dissatisfaction are mixed. Slater et al. (2017) found that women who viewed fitspiration and self-compassion images reported greater body satisfaction and body appreciation than those who viewed fitspiration images only, but these effects were not moderated by thin-ideal internalization. Similarly, in Slater et al.'s study (2019) acute exposure to parody images led to increased body satisfaction compared to exposure to the thin-ideal celebrity images alone, however the findings were not moderated by trait levels of thin-ideal internalization. Tiggemann and Velissaris (2020) found that thin-ideal internalization did not moderate the effect of thin and attractive women with different comment types (reality check vs positive appearance comments) on body dissatisfaction, but rather predicted the increase in body dissatisfaction regardless of experimental condition $(\beta=0.18)$. Finally, Tiggemann et al. (2020b) indicated that for women high on thin-ideal internalization, body positive captions on average images led to greater body appreciation, but lower body appreciation when attached to thin images $\left(\eta p^{2}=0.03\right)$.

\section{Discussion}

Although a wide number of correlational studies has found that SNS use is associated with body dissatisfaction and body image disturbance among young women and men (for 
a systematic review, see Holland \& Tiggemann, 2016; for a meta-analysis, see Saiphoo \& Vahedi, 2019), only experimental studies can enhance confidence in the conclusions drawn. However, to date no previous systematic review has been conducted on the available experimental research in this area. This study systematically examined the existing experimental studies that have investigated the effect of viewing beauty ideal images on SNSs on body image. A systematic review was deemed to be more feasible and meaningful than a meta-analysis due to wide variability in experimental stimuli and psychological moderators used in the published research.

Consistent results were found regarding the negative effect of viewing attractive ideal images on young women body satisfaction with a small to medium effect size $\left(0.02<\eta p^{2}<0.06 ; 0.21<d<0.73\right.$; Cohen, 1988). Similarly, exposure to thinspiration images predicts greater state body dissatisfaction relative to exposure to the control images with a small to large effect size $\left(0.03<\eta p^{2}<0.29\right)$. In general, as expected, body image for women was significantly more negative after viewing thin and attractive SNSs images than after viewing images of either average size/realistic/ unattractive bodies or travel and landscapes. These results confirm a relationship between SNS use and increased body dissatisfaction as previously reported by correlational studies (Holland \& Tiggemann, 2016; Saiphoo \& Vahedi, 2019). The effects of viewing beauty ideal images on body dissatisfaction reported by the experimental studies presented here were found to be similar in size to those of short-term exposure to idealized images through traditional media (Groesz et al., 2002). This finding supports the perspective that, like traditional media, appearance focused SNSs promote a standard of idealized beauty that leads many women to feel dissatisfied about their bodies (e.g., Cohen et al., 2017).

The evaluation of the exposure to fitspiration images produced mixed findings, with some studies reporting a detrimental effect on body satisfaction of medium size $\left(0.05<\eta p^{2}<0.11\right)$, whereas other studies failed to find it. The self-improvement motive for social comparison (see Helgeson \& Mickelson, 1995) might explain why fitspiration images did not causally affect body satisfaction. Building from social comparison theory, scholars affirmed that the extent and direction of the influence of media models on body perception varies depending on the motive for comparing oneself with models in the media (e.g., Halliwell \& Dittmar, 2005). In particular, when engaging in upward comparison (i.e., the type of comparison most elicited by ideal body media exposure), two types of motives occur: (i) selfevaluation, the motivation highlighted by Festinger (1954) in his original theory, involves simply judging whether one's own body resembles that in the idealized image; and (ii) self-improvement, which is the motivation and inspiration to improve oneself (Lockwood \& Kunda, 1997). On the one hand, self-evaluation comparison motivation is more likely to be responsible for the negative effect of idealized pictures on body image through experiencing self-ideal discrepancies and potential feelings of personal failure in achieving the beauty ideal. On the other hand, self-improvement comparison motivation could explain the positive effects of exposure to body ideals on body satisfaction (e.g., Halliwell \& Dittmar, 2005). It is possible that viewing fit ideal images did not produce a lower level of body satisfaction because of the occurrence of self-improvement comparison motivation that counteracts the effect of the exposure to idealized images on body satisfaction, in accordance with previous studies (e.g., Knobloch-Westerwick, 2015; Veldhuis et al., 2017). Evaluating the different motives for comparison with models' ideal bodies could help clarify the effects of fitspiration images on body satisfaction.

Although the majority of the studies included here investigated the effect of the exposure to idealized images on SNSs on the evaluative component of body image (i.e., body satisfaction/dissatisfaction), some studies evidenced a negative effect of viewing attractive and fitspiration images on some cognitive dimensions of body image, such as appearance self-esteem and psychological body investment. In accordance with the meta-analysis conducted by Saiphoo and Vahedi (2019) on correlational studies, these results suggest the importance to further investigate the impact of SNSs on more specific dimensions of body image (i.e., cognitive, behavioral, and affective), which may then indirectly impact one's general satisfaction with their body.

Regarding the effect of viewing SNSs idealized images on body appreciation, the majority of studies did not find differences in body appreciation levels across experimental and control conditions. Only one study found a small negative effect of the exposure to thin and attractive women images on body appreciation (Brown \& Tiggemann, 2020, $\left.\eta p^{2}=0.04\right)$. The impact of exposure to media imagery on body appreciation is still it its infancy (only eight studies included here have evaluated it), so it is difficult to draw conclusions. It is possible that, as a newly developed measure, the state body appreciation measure has not yet been subject to psychometric evaluation and so may be insufficiently sensitive to small changes. Body appreciation is considered a key component of positive body image and it constitutes the most common way to operationalize it. Importantly, positive body image is conceptualized as something more than just the equivalent of low negative body image, or the mere absence of body dissatisfaction (Tiggemann \& McCourt, 2013; Tylka \& Wood-Barcalow, 2015). Indeed, a number of studies have identified characteristics of positive body image that go considerably beyond body satisfaction such as optimism, a broad notion of beauty, and a functional view of the body (e.g., Wood-Barcalow et al., 2010). Therefore, it is possible that SNS idealized images, while influencing 
body satisfaction, were not relevant enough to influence body appreciation.

Although a small number of studies have examined the effect of viewing SNS idealized images on men body satisfaction, they consistently found a small to large negative effect $\left(\eta p^{2}=0.03 ; d=0.90\right)$ of viewing fitspiration images (both through one-time and multiple exposure) on body dissatisfaction, whereas a multiple exposure to attractive ideal images did not influence men body satisfaction (Casale et al., 2019). This finding could be explained by gender differences in how the ideal body is perceived. Indeed, men tend to place a greater emphasis on muscularity whereas women focus more on being thin (Grogan, 2008). Therefore, fitspiration images could be a more relevant target that men compare themselves against relative to attractive and thin images. The negative impact of viewing fitspiration images on body dissatisfaction among men suggests that this population should not be neglected when examining the relationship between SNS use and body image.

The effect of a number of individual difference mediators/ moderators on the relationship between SNS images and body dissatisfaction were also explored. State appearance comparison significantly mediated the relationship between viewing idealized images and body satisfaction and appreciation. The mediation finding indicated that the more state appearance comparison participants engaged in while viewing the beauty ideal images on SNSs, the greater the increase in body dissatisfaction and decrease in body appreciation. This finding is consistent with results reported by correlational studies (Holland \& Tiggemann, 2016), providing further support for the application of the sociocultural theory of body dissatisfaction (Thompson et al., 1999) in SNSs context. Consistently, trait appearance comparison tendency resulted to be a significant moderator of the relationship between image condition and body dissatisfaction among both women and men. For people who had a high tendency to make appearance comparisons with others, viewing idealized images on social media lead to more body dissatisfaction, relative to people with low appearance comparison tendency. This suggests that trait appearance comparison serves as a vulnerability factor for poorer body image in response to idealized images on SNSs.

The role of trait self-objectification and thin-ideal internalization as moderators between image condition and body satisfaction was less investigated by the studies presented here, with inconsistent results. The majority of studies found that both the internalization of appearance ideals and selfobjectification did not moderate the effect of image types on body dissatisfaction. However, they did predict increase in body dissatisfaction in response to viewing the images regardless of experimental condition. Therefore, they could not be judged as irrelevant. Since both internalization and self-objectification were found to explain the detrimental effect of SNSs use on body image among correlational studies (Holland \& Tiggemann, 2016), future experimental research should continue to explore their role.

Another aim of the current study was to systematically review also those experimental studies aimed to examine the effect of the exposure to body-positive images on body satisfaction and appreciation, in order to obtain some indications regarding the effectiveness of body positive content in reducing body dissatisfaction. Only four studies included in the current review investigated this issue with mixed findings. Two studies found that body positive captions attached to attractive and thin images were ineffective at improving women's body satisfaction and appreciation, suggesting that the visual imagery of an Instagram post is a more potent contributor to body image than any accompanying text (Brown \& Tiggemann, 2020; Tiggemann et al., 2020b). Indeed, when the effect of viewing body positive images was investigated, improvements in young women's body satisfaction $\left(\eta p^{2}=0.34\right)$ and body appreciation $\left(\eta p^{2}=0.07\right)$, relative to thin-ideal and appearance-neutral posts were found with medium and large effect sizes (Cohen et al., 2019). Further experimental studies are needed to confirm these promising initial findings regarding the positive short-term effect of viewing body positive content on SNSs on women's body image. Moreover, the underlying mechanisms should be clarified. For example, Tiggemann et al. (2020b) found that for women high on thin internalization, the body positive captions led to increased body appreciation when attached to average figures, but lower body appreciation when attached to thin figures. In other words, body positive captions when attached to thin images could be counterproductive for some women, namely those high on thin-ideal internalization. Future research might explicitly investigate how women receive and interpret body positive messages.

\section{Limitations of the Literature and Future Research}

Although the quality assessment revealed that most studies were of high quality, there are still several limitations to the existing experimental research on idealized models of beauty on SNSs and body image. The first set of limitations is in regard to the characteristics of samples most commonly used. Results of studies reviewed only generalize to primarily Caucasian, normal weight women between the ages of 14-25 years who are undergraduate students and come from Australia or United States. Future research should investigate the effect of the exposure to SNS idealized images among diverse samples of adolescents, older women, women of other racial or ethnic backgrounds, with underweight or overweight body size, and with other education level. Moreover, men are under-represented and further 
studies are needed on the relationship between SNSs use and men's body image. One important developmental finding that needs to be discussed is that experimental research in this area has essentially excluded adolescents. Indeed, only two studies were conducted among adolescents whereas the remaining studies examined the effect of the exposure to SNSs idealized images on body dissatisfaction among young adults. This is a point that is worth highlighting since adolescence represents a critical period for body image concerns and body dissatisfaction because of the physical, cognitive, and social changes that unfold during this developmental period and for the great vulnerability of adolescents for being influenced by media (e.g., Jones \& Smolak, 2011). Moreover, the frequent use of social media networks such as Instagram among adolescents (AP-NORC, 2017; Eurostat, 2021) clearly stresses the importance of studying the effects of exposure. Since the central role body image plays in the development, future experimental studies should investigate how the exposure to beauty ideals on SNSs influences adolescents' body image.

Another limitation is that all but three of the studies reviewed adopted a one-time exposure procedure with SNSs images presented for few minutes. Stronger effects may occur if participants were to view images over a longer timeframe, as typically experienced when using SNSs in everyday life. Additionally, the majority of studies were conducted in laboratory settings and so, despite using strategies to increase ecological validity (e.g., using images sourced from public SNS profiles and placed within the SNS frame) viewing social media posts in an experimental context might not replicate real-world effects. Therefore, real-life effects of viewing SNSs idealized images may be larger than what found in the studies presented here. More longitudinal research is needed to examine the prolonged effect of exposure to SNSs images on women's body image. In particular, research designs utilizing ecological momentary assessment (EMA) methods, with multiple follow-up points, would be informative to ascertain how long-lasting the effects of images on an individual's body image are, in a more naturalistic and ecologically valid setting. Finally, the role of potential moderators, such as trait self-objectification and thin-ideal internalization, needs to be further explored.

\section{Implications}

Although more research is required to assess the longer-term effects, some important implications can be drawn. From a theoretical point of view, the results provide additional support to the sociocultural model (Thompson et al., 1999), which propose social comparison as an important mechanism by which media ideals negatively affect body image, extending its application to a new medium, that are SNSs. At a practical level, there is quite a strong scientific basis for social media literacy programs that aim to reduce social comparison to unrealistic images that idealize thinness, fitness and appearance perfection, and its negative effect on body image among young people. Unlike traditional media whereby users are passive consumers, SNS users are active in deciding what they post and who they follow. Therefore, as an initial step, it could be helpful to encourage the youth to follow more body positive accounts to counterbalance the many idealized images they typically view every day on SNSs. Finally, the results of this systematic review indicate a key future area of research that has thus far remained underdeveloped, that is the influence of the exposure to SNSs beauty ideals on adolescent's body image. A clear understanding of the trajectories of body dissatisfaction among diverse female and male youth, as well as the examination of the different mechanisms involved, will inform prevention efforts aimed at intervening in these trajectories and mitigating harmful outcomes.

\section{Conclusion}

The negative influence of using and being exposed to SNSs on body image has been evidenced by a wide number of correlational studies. To enhance the conclusions drawn from correlational research, a growing body of experimental studies testing whether body dissatisfaction and body image concerns increased after the exposure to different types of beauty ideals images on SNSs (in comparison to viewing appearance-neutral images), has been conducted. To date, no previous study has systematically reviewed the empirical contribution of the experimental research conducted on this topic. Hence the present study systematically examined the existing studies that have investigated the relationship between SNSs use and body image using experimental research designs. Overall, the results consistently reflect that viewing images on SNSs depicting unattainable beauty ideals (i.e., thin, attractive, and fit) has a negative effect on body image. In particular, a brief exposure to thin and attractive ideal images on SNSs causes body dissatisfaction among young female viewers. Moreover, a negative effect of fitspiration images on young men's body satisfaction also emerged. Appearance comparison processing plays a relevant role in explaining the detrimental effect of being exposed to SNS idealized images on body satisfaction. Preliminary evidence has emerged regarding the effectiveness of body positive content in reducing body dissatisfaction. Results of the individual studies included in the current systematic review need to be considered in the context of their limitations. In particular, the characteristics of the samples most used limit the generalizability of the results. It is to be noted that most of the studies in this research area did not focus on adolescents, the group that is typically seen as most 
at risk for media influences. Previous correlational studies evidenced that the relationship between social media use and body image disturbance is strengthened as the mean age of the sample decreases (Saiphoo \& Vahedi, 2019). Moreover, adolescence represents a pivotal stage in the development of positive or negative body image. Although further data are needed, it is expected that being exposed to idealized bodies on SNSs could be particularly problematic for adolescents' body image, since they are more engaged in the development task of shaping their body image in comparison to (young) adults.

Acknowledgements The authors would like to express their gratitude to the Editor of Adolescent Research Review, Roger J. R. Levesque, who provided valuable comments on the article.

Authors' Contributions GF conceived the study, participated in its design and coordination, interpreted the data, and drafted the manuscript; SBB performed the literature search, data screening and extraction, provided summaries of research studies and helped to draft the manuscript; GC performed the literature search, data screening and extraction; SC conceived the study and supervised it, revised and edited the manuscript. All authors read and approved the final manuscript.

\section{Declarations}

Conflicts of interest The authors have no conflicts of interest to declare that are relevant to the content of this article.

Open Access This article is licensed under a Creative Commons Attribution 4.0 International License, which permits use, sharing, adaptation, distribution and reproduction in any medium or format, as long as you give appropriate credit to the original author(s) and the source, provide a link to the Creative Commons licence, and indicate if changes were made. The images or other third party material in this article are included in the article's Creative Commons licence, unless indicated otherwise in a credit line to the material. If material is not included in the article's Creative Commons licence and your intended use is not permitted by statutory regulation or exceeds the permitted use, you will need to obtain permission directly from the copyright holder. To view a copy of this licence, visit http://creativecommons.org/licenses/by/4.0/.

\section{References}

Alanazi, A. S., Alotaibi, Y. M., Alojan, J. S., \& Zaidi, U. (2019). Effects of social media contents on the perception of body image. International Journal of Innovation, Creativity and Change, 9(7), 179-196.

American Dietetic Association. (2005). ADA evidence analysis manual. American Dietetic Association.

Andrew, R., Tiggemann, M., \& Clark, L. (2015). The protective role of body appreciation against media-induced body dissatisfaction. Body Image, 15, 98-104. https://doi.org/10.1016/j.bodyim.2015. 07.005

AP-NORC. (2017). Instagram and Snapchat are the most popular social networks for teens; black teens are most active on social media, Messaging Apps. Retrieved November 3, 2021, from https:// apnorc.org/projects/instagram-and-snapchat-are-most-popul ar-social-networks-for-teens-black-teens-are-most-active-onsocial-media-messaging-apps/

Avalos, L., Tylka, T. L., \& Wood-Barcalow, N. (2005). The body appreciation scale: Development and psychometric evaluation. Body Image, 2(3), 285-297. https://doi.org/10.1016/j.bodyim.2005.06. 002

Barlett, C. P., Vowels, C. L., \& Saucier, D. A. (2008). Meta-analyses of the effects of media images on men's body-image concerns. Journal of Social and Clinical Psychology, 27(3), 279-310. https://doi. org/10.1521/jscp.2008.27.3.279

Brichacek, A. L., Neill, J. T., \& Murray, K. (2018). The effect of basic psychological needs and exposure to idealised Facebook images on university students' body satisfaction. Cyberpsychology: Journal of Psychosocial Research on Cyberspace, 12(3), 1-13. https:// doi.org/10.5817/CP2018-3-2

Brown, Z., \& Tiggemann, M. (2016). Attractive celebrity and peer images on Instagram: Effect on women's mood and body image. Body Image, 19, 37-43. https://doi.org/10.1016/j.bodyim.2016. 08.007

Brown, Z., \& Tiggemann, M. (2020). A picture is worth a thousand words: The effect of viewing celebrity Instagram images with disclaimer and body positive captions on women's body image. Body Image, 33, 190-198. https://doi.org/10.1016/j.bodyim.2020. 03.003

Brownell, K. D., \& Walsh, B. T. (2017). Eating disorders and obesity: A comprehensive handbook. Guilford Publications.

Bucchianeri, M., \& Neumark-Sztainer, D. (2014). Body dissatisfaction: An overlooked public health concern. Journal of Public Mental Health, 13(2), 64-69. https://doi.org/10.1108/ JPMH-11-2013-0071

Buhrmester, M., Kwang, T., \& Gosling, S. (2011). Amazon's Mechanical Turk: A new source of inexpensive, yet high-quality data? Perspectives on Psychological Science, 6, 3-5. https://doi.org/10. 1177/1745691610393980

Carrotte, E. R., Prichard, I., \& Lim, M. S. C. (2017). "Fitspiration" on social media: A content analysis of gendered images. Journal of Medical Internet Research, 19(3), 1-9. https://doi.org/10.2196/ jmir.6368

Casale, S., Gemelli, G., Calosi, C., Giangrasso, B., \& Fioravanti, G. (2019). Multiple exposure to appearance-focused real accounts on Instagram: Effects on body image among both genders. Current Psychology. https://doi.org/10.1007/s12144-019-00229-6

Cash, T., Fleming, E. C., Alindogan, J., Steadman, L., \& Whitehead, A. (2002). Beyond body image as a trait: The development and validation of the body image states scale. Eating Disorders, 10, 103-113. https://doi.org/10.1080/10640260290081678

Cash, T. F. (2000). Multidimensional body-self relations questionnaire: MBSRQ user's manual. Old Dominion University.

Cash, T. F., \& Szymanski, M. L. (1995). Body-image disturbance and self-discrepancy theory: Expansion of the Body-Image Ideals Questionnaire. Journal of Social and Clinical Psychology, 14, 134-146. https://doi.org/10.1521/jscp.1995.14.2.134

Chansiri, K., Wongphothiphan, T., \& Shafer, A. (2020). The indirect effects of thinspiration and fitspiration images on young women's sexual attitudes. Communication Research. https://doi.org/10. 1177/0093650220952231

Cohen, J. (1988). Statistical Power Analysis for the Behavioral Sciences. Routledge Academic.

Cohen, R., Fardouly, J., Newton-John, T., \& Slater, A. (2019). \# BoPo on Instagram: An experimental investigation of the effects of viewing body positive content on young women's mood and body image. New Media \&amp; Society, 21(7), 1546-1564. https://doi. org/10.1177/1461444819826530

Cohen, R., Newton-John, T., \& Slater, A. (2017). The relationship between Facebook and Instagram appearance-focused activities 
and body image concerns in young women. Body Image, 23, 183187. https://doi.org/10.1016/j.bodyim.2017.10.002

Couture Bue, A. C., \& Harrison, K. (2020). Visual and cognitive processing of thin-ideal Instagram images containing idealized or disclaimer comments. Body Image, 33, 152-163. https://doi.org/ 10.1016/j.bodyim.2020.02.014

Crow, S., Eisenberg, M. E., Story, M., \& Neumark-Sztainer, D. (2008). Suicidal behavior in adolescents: Relationship to weight status, weight control behaviors, and body dissatisfaction. The International Journal of Eating Disorders, 41, 82-87. https://doi.org/10. 1002/eat.20466

Cwynar-Horta, J. (2016). The commodification of the body positive movement on Instagram. Stream: Interdisciplinary Journal of Communication, 8(2), 36-56. https://doi.org/10.21810/strm.v8i2. 203

Davies, B., Turner, M., \& Udell, J. (2020). Add a comment... how fitspiration and body positive captions attached to social media images influence the mood and body esteem of young female Instagram users. Body Image, 33, 101-105. https://doi.org/10.1016/j. bodyim.2020.02.009

Eurostat. (2021). Are you using social networks? Retrieved November 3, 2021, from https://ec.europa.eu/eurostat/web/productseurostatnews/-/EDN-20190629-1

Fardouly, J., \& Holland, E. (2018). Social media is not real life: The effect of attaching disclaimer-type labels to idealized social media images on women's body image and mood. New Media \&amp; Society, 20(11), 4311-4328. https://doi.org/10.1177/1461444818 771083

Fardouly, J., \& Rapee, R. M. (2019). The impact of no-makeup selfies on young women's body image. Body Image, 28, 128-134. https:// doi.org/10.1016/j.bodyim.2019.01.006

Festinger, L. (1954). A theory of social comparison processes. Human Relations, 7(2), 117-140. https://doi.org/10.1177/0018726754 00700202

Fiske, L., Fallon, E. A., Blissmer, B., \& Redding, C. A. (2014). Prevalence of body dissatisfaction among United States adults: Review and recommendations for future research. Eating Behaviors, 15(3), 357-365. https://doi.org/10.1016/j.eatbeh.2014.04.010

Flynn, M. A. (2016). The effects of profile pictures and friends' comments on social network site users' body image and adherence to the norm. Cyberpsychology, Behavior, and Social Networking, 19(4), 239-245. https://doi.org/10.1089/cyber.2015.0458

Frederick, D. A., Buchanan, G. M., Sadehgi-Azar, L., Peplau, L. A., Haselton, M. G., Berezovskaya, A., \& Lipinski, R. E. (2007). Desiring the muscular ideal: Men's body satisfaction in the United States, Ukraine, and Ghana. Psychology of Men \&amp; Masculinity, 8, 103-117. https://doi.org/10.1037/1524-9220.8.2.103

Fredrickson, B. L., \& Roberts, T. A. (1997). Objectification theory: Toward understanding women's lived experiences and mental health risks. Psychology of Women Quarterly, 21, 173-206. https://doi.org/10.1111/j.1471-6402.1997.tb00108.x

Garner, D. M., Olmstead, M., \& Polivy, J. (1983). Development and validation of a multidimensional eating disorder inventory for anorexia nervosa and bulimia. International Journal of Eating Disorders, 2(2), 15-34. https://doi.org/10.1002/1098-108X(198321) 2:2\%3c15::AID-EAT2260020203\%3e3.0.CO;2-6

Garrow, J. S., \& Webster, J. (1984). Quetelet's index (W/H2) as a measure of fatness. International Journal of Obesity, 9, 147-153.

Goldfield, G. S., Moore, C., Henderson, K., Buchholz, A., Obeid, N., \& Flament, M. F. (2010). Body dissatisfaction, dietary restraint, depression, and weight status in adolescents. Journal of School Health, 80(4), 186-192. https://doi.org/10.1111/j.1746-1561. 2009.00485.x

Grabe, S., Ward, L. M., \& Hyde, J. S. (2008). The role of the media in body image concerns among women: A meta-analysis of experimental and correlational studies. Psychological Bulletin, 134, 460-476. https://doi.org/10.1037/0033-2909.134.3.460

Griffiths, S., Hay, P., Mitchison, D., Mond, J. M., McLean, S. A., Rodgers, B., Massey, R., \& Paxton, S. J. (2016). Sex differences in the relationships between body dissatisfaction, quality of life and psychological distress. Australian and New Zealand Journal of Public Health, 40(6), 518-522. https://doi.org/10.1111/1753-6405.12538

Griffiths, S., \& Stefanovski, A. (2019). Thinspiration and fitspiration in everyday life: An experience sampling study. Body Image, 30, 135-144. https://doi.org/10.1016/j.bodyim.2019.07.002

Groesz, L. M., Levine, M. P., \& Murnen, S. K. (2002). The effect of experimental presentation of thin media images on body satisfaction: A meta-analytic review. International Journal of Eating Disorders, 31(1), 1-16. https://doi.org/10.1002/eat.10005

Grogan, S. (2008). Body image: Understanding body dissatisfaction in men, women and children (2nd ed.). Routledge.

Halliwell, E. (2013). The impact of thin idealized media images on body satisfaction: Does body appreciation protect women from negative effects? Body Image, 10(4), 509-514. https://doi.org/10. 1016/j.bodyim.2013.07.004

Halliwell, E., \& Dittmar, H. (2005). The role of self-improvement and self-evaluation motives in social comparisons with idealised female bodies in the media. Body Image, 2, 249-261. https://doi. org/10.1016/j.bodyim.2005.05.001

Harper, B., \& Tiggemann, M. (2008). The effect of thin ideal media images on women's self-objectification, mood, and body image. Sex Roles, 58, 649-657. https://doi.org/10.1007/ s11199-007-9379-x

Helgeson, V. S., \& Mickelson, K. D. (1995). Motives for social comparison. Personality \&amp; Social Psychology Bulletin, 21, 12001209. https://doi.org/10.1177/01461672952111008

Hogue, J. V., \& Mills, J. S. (2019). The effects of active social media engagement with peers on body image in young women. Body Image, 28, 1-5. https://doi.org/10.1016/j.bodyim.2018.11.002

Holland, G., \& Tiggemann, M. (2016). A systematic review of the impact of the use of social networking sites on body image and disordered eating outcomes. Body Image, 17, 100-110. https:// doi.org/10.1016/j.bodyim.2016.02.008

Homan, K. J. (2016). Factor structure and psychometric properties of a state version of the Body Appreciation Scale-2. Body Image, 19, 204-207. https://doi.org/10.1016/j.bodyim.2016.10.004

Jones, D. C., \& Smolak, L. (2011). Body image during adolescence: A developmental perspective. In B. B. Brown \& M. J. Prinstein (Eds.), Encyclopedia of adolescence (pp. 77-86). Academic Press.

Kaplan, A. M., \& Haenlein, M. (2010). Users of the world, unite! The challenges and opportunities of social media. Business Horizons, 53, 59-68. https://doi.org/10.1016/j.bushor.2009.09.003

Kim, H. M. (2020). What do others' reactions to body posting on Instagram tell us? The effects of social media comments on viewers' body image perception. New Media \&amp; Society. https://doi. org/10.1177/1461444820956368

Kim, M., \& Park, W. (2016). Who is at risk on Facebook? The effects of Facebook News Feed photographs on female college students' appearance satisfaction. The Social Science Journal, 53(4), 427434. https://doi.org/10.1016/j.soscij.2016.08.007

Kleemans, M., Daalmans, S., Carbaat, I., \& Anschütz, D. (2018). Picture perfect: The direct effect of manipulated Instagram photos on body image in adolescent girls. Media Psychology, 21(1), 93-110. https://doi.org/10.1080/15213269.2016.1257392

Knobloch-Westerwick, S. (2015). Thinspiration: Self-improvement versus self-evaluation social comparisons with thin-ideal media portrayals. Health Communication, 30, 1089-1101. https://doi. org/10.1080/10410236.2014.921270

Krug, I., Selvaraja, P., Fuller-Tyszkiewicz, M., Hughes, E. K., Slater, A., Griffiths, S., Yee, Z. W., Richardson, B., \& Blake, K. (2020). The effects of fitspiration images on body attributes, mood and 
eating behaviors: An experimental Ecological Momentary Assessment study in females. Body Image, 35, 279-287. https://doi.org/ 10.1016/j.bodyim.2020.09.011

Levy, R., \& Blaszczynski, A. (2015). Comparative effects of Facebook and conventional media on body image dissatisfaction. Journal of Eating Disorders, 3(1), 23. https://doi.org/10.1186/ s40337-015-0061-3

Liberati, A., Altman, D. G., Tetzlaff, J., Mulrow, C., Gotzsche, P. C., Ioannidis, J. P. A., Clarke, M., Devereaux, P. J., Kleijnen, J., \& Moher, D. (2015) PRISMA Stetement per il reporting di revisioni sistematiche e meta-analisi degli studi che valutano gli interventi sanitari: spiegazione ed elaborazione. Evidence, 7(6), 1-36. https://doi.org/10.4470/E1000115

Livingston, J., Holland, E., \& Fardouly, J. (2020). Exposing digital posing: The effect of social media self-disclaimer captions on women's body dissatisfaction, mood, and impressions of the user. Body Image, 32, 150-154. https://doi.org/10.1016/j.bodyim.2019. 12.006

Lockwood, P., \& Kunda, Z. (1997). Superstars and me: Predicting the impact of role models on the self. Journal of Personality \&amp; Social Psychology, 73, 91-103. https://doi.org/10.1037/00223514.73.1.91

McComb, S. E., \& Mills, J. S. (2020). A systematic review on the effects of media disclaimers on young women's body image and mood. Body Image, 32, 34-52. https://doi.org/10.1016/j.bodyim. 2019.10.010

Mills, J. S., Musto, S., Williams, L., \& Tiggemann, M. (2018). "Selfie" harm: Effects on mood and body image in young women. Body Image, 27, 86-92. https://doi.org/10.1016/j.bodyim.2018.08.007

Myers, E. F., Parrott, J. S., Cummins, D. S., \& Splett, P. (2011). Funding source and research report quality in nutrition practice-related research. PLoS ONE, 6(12), 1-13. https://doi.org/10.1371/journ al.pone. 0028437

Politte-Corn, M., \& Fardouly, J. (2020). \# nomakeupselfie: The impact of natural no-makeup images and positive appearance comments on young women's body image. Body Image, 34, 233-241. https:// doi.org/10.1016/j.bodyim.2020.07.001

Prichard, I., Kavanagh, E., Mulgrew, K. E., Lim, M. S., \& Tiggemann, M. (2020). The effect of Instagram\# fitspiration images on young women's mood, body image, and exercise behaviour. Body Image, 33, 1-6. https://doi.org/10.1016/j.bodyim.2020.02.002

Prichard, I., McLachlan, A. C., Lavis, T., \& Tiggemann, M. (2018). The impact of different forms of\# fitspiration imagery on body image, mood, and self-objectification among young women. Sex Roles, 78(11-12), 789-798. https://doi.org/10.1007/s11199-017-0830-3

Qi, W., \& Cui, L. (2018). Being successful and being thin: The effects of thin-ideal social media images with high socioeconomic status on women's body image and eating behaviour. Journal of Pacific Rim Psychology, 12(8), 1-9. https://doi.org/10.1017/prp.2017.16

Robinson, L., Prichard, I., Nikolaidis, A., Drummond, C., Drummond, M., \& Tiggemann, M. (2017). Idealised media images: The effect of fitspiration imagery on body satisfaction and exercise behaviour. Body Image, 22, 65-71. https://doi.org/10.1016/j.bodyim. 2017.06.001

Saiphoo, A. N., \& Vahedi, Z. (2019). A meta-analytic review of the relationship between social media use and body image disturbance. Computers in Human Behavior, 101, 259-275. https://doi. org/10.1016/j.chb.2019.07.028

Sampson, A., Jeremiah, H. G., Andiappan, M., \& Newton, J. T. (2020). The effect of viewing randomize smile images versus nature images via social media on immediate facial satisfaction in young adults: A randomized controlled trial. Journal of Orthodontics, 47(1), 55-64. https://doi.org/10.1177/1465312519899664

Santhira, S. P., Harris, N., Boddy, J., \& Donovan, C. L. (2018). The relationship between body image concerns and weight-related behaviours of adolescents and emerging adults: A systematic review. Behaviour Change, 34, 208-252. https://doi.org/10.1017/ bec. 2018.3

Sastre, A. (2014). Towards a Radical Body Positive. Feminist Media Studies, 14, 929-943. https://doi.org/10.1080/14680777.2014. 883420

Serlin, D. (2020). The effects of exposure to body positive and fitspiration Instagram Content on Undergraduate Women's State Body Satisfaction, State Body Appreciation, and Mood. MSc Thesis, Arizona State University.

Sherlock, M., \& Wagstaff, D. L. (2018). Exploring the relationship between frequency of Instagram use, exposure to idealized images, and psychological well-being in women. Psychology of Popular Media Culture, 8(4), 482-490. https://doi.org/10.1037/ ppm0000182

Slade, P. D., Dewey, M. E., Newton, T., Brodie, D., \& Kiemle, G. (1990). Development and preliminary validation of the Body Satisfaction Scale (BSS). Psychology and Health, 4(3), 213-220. https://doi.org/10.1080/08870449008400391

Slater, A., Cole, N., \& Fardouly, J. (2019). The effect of exposure to parodies of thin-ideal images on young women's body image and mood. Body Image, 29, 82-89. https://doi.org/10.1016/j. bodyim.2019.03.001

Slater, A., Varsani, N., \& Diedrichs, P. C. (2017). \# fitspo or\# loveyourself? The impact of fitspiration and self-compassion Instagram images on women's body image, self-compassion, and mood. Body Image, 22, 87-96. https://doi.org/10.1016/j. bodyim.2017.06.004

Stice, E., Schupak-Neuberg, E., Shaw, H., \& Stein, R. (1994). Relation of mediaexposure to eating disorder symptomatology: An examination of mediating mechanisms. Journal of Abnormal Psychology, 103, 836-840. https://doi.org/10.1037/0021-843X. 103.4.836

Tamplin, N. C., McLean, S. A., \& Paxton, S. J. (2018). Social media literacy protects against the negative impact of exposure to appearance ideal social media images in young adult women but not men. Body Image, 26, 29-37. https://doi.org/10.1016/j.bodyim. 2018.05.003

Taniguchi, E., \& Lee, H. E. (2012). Cross-cultural differences between Japanese and American female college students in the effects of witnessing fat talk on Facebook. Journal of Intercultural Communication Research, 41(3), 260-278. https://doi.org/10.1080/ 17475759.2012.728769

Taniguchi, E., \& Lee, H. E. (2013). Effect of witnessing fat talk on body satisfaction and psychological well-being: A cross-cultural comparison of Korea and the United States. Social Behavior and Personality, 41(8), 1279-1296. https://doi.org/10.2224/sbp.2013. 41.8.1279

Thompson, J. K., Heinberg, L. J., Altabe, M., \& Tantleff-Dunn, S. (1999). Exacting beauty: Theory, assessment, and treatment of body image disturbance. American Psychological Association.

Thompson, M. A., \& Gray, J. J. (1995). Development and validation of a new body-image assessment scale. Journal of Personality Assessment, 64, 258-269. https://doi.org/10.1207/s15327752j pa6402_6

Tiggemann, M. (2002). Media influences on body image development. In T. Cash \& T. Pruzinsky (Eds.), Body image: A handbook of theory, research, and clinical practice (pp. 91-98). Guilford Press.

Tiggemann, M., \& Anderberg, I. (2019). Social media is not real: The effect of 'Instagram vs reality' images on women's social comparison and body image. New Media \&amp; Society, 22(12), 2183-2199. https://doi.org/10.1177/1461444819888720

Tiggemann, M., Anderberg, I., \& Brown, Z. (2020a). Uploading your best self: Selfie editing and body dissatisfaction. Body Image, 33, 175-182. https://doi.org/10.1016/j.bodyim.2020.03.002

Tiggemann, M., Anderberg, I., \& Brown, Z. (2020b). \# Loveyourbody: The effect of body positive Instagram captions on women's body 
image. Body Image, 33, 129-136. https://doi.org/10.1016/j.bodyim.2020.02.015

Tiggemann, M., \& Barbato, I. (2018). "You look great!”: The effect of viewing appearance-related Instagram comments on women's body image. Body Image, 27, 61-66. https://doi.org/10.1016/j. bodyim.2018.08.009

Tiggemann, M., Hayden, S., Brown, Z., \& Veldhuis, J. (2018). The effect of Instagram "likes" on women's social comparison and body dissatisfaction. Body Image, 26, 90-97. https://doi.org/10. 1016/j.bodyim.2018.07.002

Tiggemann, M., \& McCourt, A. (2013). Body appreciation in adult women: Relationships with age and body satisfaction. Body Image, 10, 624-627. https://doi.org/10.1016/j.bodyim.2013.07. 003

Tiggemann, M., \& Velissaris, V. G. (2020). The effect of viewing challenging "reality check" Instagram comments on women's body image. Body Image, 33, 257-263. https://doi.org/10.1016/j. bodyim.2020.04.004

Tiggemann, M., \& Zaccardo, M. (2015). "Exercise to be fit, not skinny": The effect of fitspiration imagery on women's body image. Body Image, 15, 61-67. https://doi.org/10.1016/j.bodyim. 2015.06.003

Tiggemann, M., \& Zinoviev, K. (2019). The effect of\# enhancementfree Instagram images and hashtags on women's body image. Body Image, 31, 131-138. https://doi.org/10.1016/j.bodyim.2019. 09.004

Tylka, T. L., \& Wood-Barcalow, N. L. (2015). What is and what is not positive body image? Conceptual foundations and construct definition. Body Image, 14, 118-129. https://doi.org/10.1016/j. bodyim.2015.04.001

Veldhuis, J., Konijn, E. A., \& Knobloch-Westerwick, S. (2017). Boost your body: Self-improvement magazine messages increase body satisfaction in young adults. Health Communication, 32, 200-210. https://doi.org/10.1080/10410236.2015.1113482

Veldhuis, J., Konijn, E. A., \& Seidell, J. C. (2014). Negotiated media effects. Peer feedback modifies effects of media's thin-body ideal on adolescent girls. Appetite, 73, 172-182. https://doi.org/10. 1016/j.appet.2013.10.023

Wood-Barcalow, N. L., Tylka, T. L., \& Augustus-Horvath, C. L. (2010). "But I like my body": Positive body image characteristics and a holistic model for young-adult women. Body Image, 7(2), 106-116. https://doi.org/10.1016/j.bodyim.2010.01.001

Yee, Z. W., Griffiths, S., Fuller-Tyszkiewicz, M., Blake, K., Richardson, B., \& Krug, I. (2020). The differential impact of viewing fitspiration and thinspiration images on men's body image concerns: An experimental ecological momentary assessment study. Body Image, 35, 96-107. https://doi.org/10.1016/j.bodyim.2020.08.008

Publisher's Note Springer Nature remains neutral with regard to jurisdictional claims in published maps and institutional affiliations. 